\title{
Modeling, Simulation and Design of Dye Sensitized Solar Cells
}

\author{
José Maçaira, Luísa Andrade*, Adélio Mendes* \\ LEPAE - Departamento de Engenharia Química, Universidade do Porto - Faculdade de \\ Engenharia, Rua Dr. Roberto Frias, s/n 4200-465 Porto, Portugal \\ landrade@fe.up.pt,mendes@fe.up.pt
}

\begin{abstract}
It is well known that recombination and transport rule the performance of dye sensitized solar cells (DSC's); although, the influence that these two phenomena have in their performance, particularly in the open circuit-potential $\left(V_{o c}\right)$ and in the short circuit current $\left(J_{s c}\right)$, is not fully understood. In this paper a phenomenological model is used to describe the quantitatively effect that transport and recombination have in the performance of the solar cell and their influence in its optimal design. The model is used to predict the influence of the recombination reaction rate constant $\left(k_{r}\right)$ and diffusion coefficient $\left(D_{e f f}\right)$ in the $V_{o c}$ and in the $J_{s c}$, whether a linear or non-linear recombination kinetic is considered. It is provided a methodology for decoupling the conduction band shifts from recombination effect in charge extraction experiments. Results also suggest that the influence of recombination in the $V_{o c}$ and in $J_{s c}$ is highly dependent on the reaction order considered. This fact highlights the importance of considering the reaction order when modeling data obtained by experimental methods. The combined results are analyzed and discussed in terms of the collection efficiency and in the optimization of the photoelectrode thickness. The model provides also a useful framework for exploring new concepts and designs for improving DSCs performance.
\end{abstract}

\section{Introduction}

The dye sensitized solar cell (DSC) is a potentially low cost photovoltaic technology that recently has achieved $12 \%$ efficiency by two different approaches ${ }^{1,2}$. A very recent work reported an energy conversion efficiency of $15 \%$ for a new sensitized solar cell ${ }^{3}$. This world 
record has been announced by M. Gräztel at the Hybrid and Organic Photovoltaic conference (HOPV 2013) meeting held in Seville in 2013 and has been certified as $14 \%$ of energy efficiency by Newport Corporation ${ }^{3}$. Dye sensitized solar cells (DSCs) mimic natural photosynthesis and differ from conventional p-n junction devices because light collection and charge transport are separated in the cell ${ }^{4}$. Light absorption occurs in the chemisorbed sensitizer molecule, while electron transport occurs in the semiconductor. The photo conversion energy efficiency $(\eta)$ of the solar cell is determined by its current-potential characteristics, specifically the open-circuit photopotential $\left(V_{o c}\right)$, the photocurrent density measured under short-circuit conditions $\left(J_{s c}\right)$, the intensity of incident light $\left(I_{s}\right)$ and the fill factor of the cell $(F F)$. The working principles of DSCs, illustrated in Figure 1, can be summarized in the following steps:

a. Light harvesting: photon absorption by dye molecules adsorbed in a monolayer on the surface of the mesoporous semiconductor (typically $\mathrm{TiO}_{2}$ ); electrons from the ground state $(\mathrm{S})$ are promoted to the excited state $\left(\mathrm{S}^{*}, k_{11}\right)$ :

$$
\mathrm{S} \underset{k_{12}}{\stackrel{h v, k_{11}}{\rightleftarrows}} \mathrm{S}^{*}
$$

b. Injection: the excited electrons are injected into the conduction band of the semiconductor $\left(k_{21}\right)$, resulting in the oxidation of the sensitizer $\left(\mathrm{S}^{+}\right)$:

$$
\mathrm{S}^{*} \underset{k_{22}}{\stackrel{k_{21}}{\rightleftarrows}} \mathrm{S}^{+}+\mathrm{e}_{C B}^{-}
$$

c. Dye regeneration: reduction of the oxidized sensitizer $\left(\mathrm{S}^{+}\right)$to its original state $(\mathrm{S})$ by electron donation from $\mathrm{I}^{-}$present in the liquid electrolyte, producing $\mathrm{I}_{3}^{-}\left(k_{3}\right)$ :

$$
\mathrm{S}^{+}+\frac{3}{2} \mathrm{I}^{-} \stackrel{k_{3}}{\longrightarrow} \frac{1}{2} \mathrm{I}_{3}^{-}+\mathrm{S}
$$

d. Collection: diffusive collection of electrons from the mesoporous semiconductor to the transparent conductive oxide (TCO) where they become available for electrical work in the external circuit; 
e. Electrolyte mass transfer: diffusive transport of the reduced $\mathrm{I}_{3}^{-}$and oxidized $\mathrm{I}^{-}$through the pores of the semiconductor to and from the counter electrode (usually coated with a platinum catalyst);

f. Electrolyte regeneration: at the counter electrode the platinum catalyst reduces the oxidized $\mathrm{I}_{3}^{-}$back to $\mathrm{I}^{-}$by reaction with a low energy electron from the external circuit $\left(k_{4}\right):$

$$
\mathrm{I}_{3}^{-}+2 \mathrm{e}^{-} \stackrel{P t, k 4}{\longrightarrow} 3 \mathrm{I}^{-}
$$

During this series of reactions, there are also processes that are unfavorable to the DSC performance:

g. Decay of dye excited state: decay of the excited state of the dye $\left(\mathrm{S}^{+}\right)$to the ground state (S) before electron injection in the conduction band of the semiconductor. This reaction $\left(k_{12}\right)$ competes directly with the injection step $\left(k_{21}\right)$;

h. Electron-dye recombination $\left(k_{22}\right)$ : reaction between the oxidized dye molecules $\left(\mathrm{S}^{+}\right)$ with electrons in the conduction band of the $\mathrm{TiO}_{2}$. This competes with dye regeneration $\left(k_{3}\right)$ and with collection of electrons from the $\mathrm{TiO}_{2}(\mathrm{~d})$;

i. Electron-electrolyte recombination: reaction of conduction band electrons with electrolyte species. This reaction competes with electron collection (d).

$$
\mathrm{I}_{3}^{-}+2 \mathrm{e}_{C B}^{-} \stackrel{k_{5}}{\longrightarrow} 3 \mathrm{I}^{-}
$$




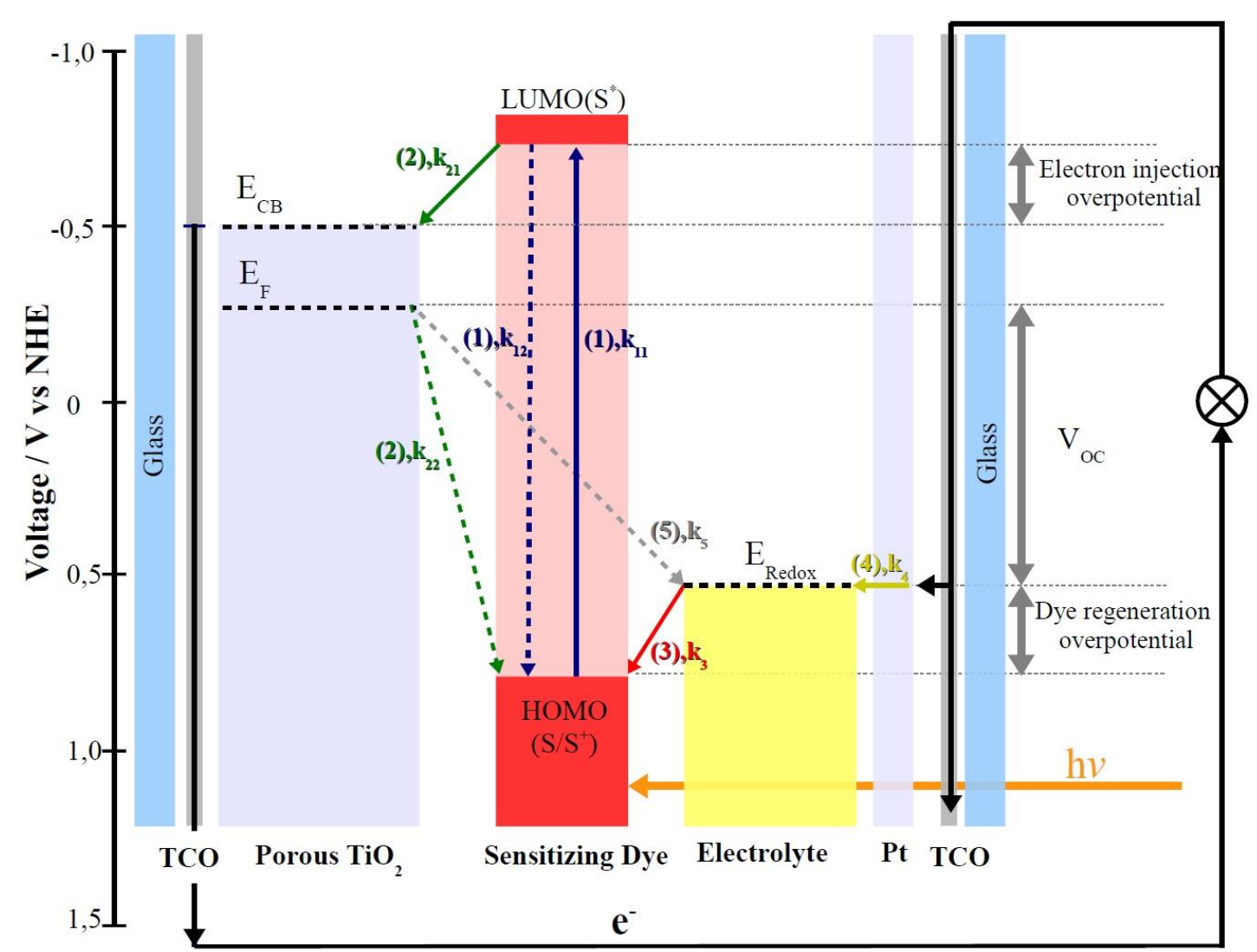

Fig. 1 Illustration of DSC's working principles. The full arrows represent the forward electron transfer reactions; the dashed arrows represent electron losses routes.

For solar cell to produce electrical energy, the forward electron transfer reactions $\left(k_{11}\right.$, $k_{21}, k_{3}$ and $\left.k_{4}\right)$ must overcome the possible electron lost pathways $\left(k_{12}, k_{22}\right.$ and $\left.k_{5}\right)$. The time constant ranges of each reaction are illustrated in Figure $2^{5}$. The recombination reaction of electrons with electrolyte species $\left(k_{5}\right)$ is considered to be one of the most important energy efficiency bottlenecks. Because the electrolyte is present throughout all the porous structure of the semiconductor, the recombination reaction is affected by the photoelectrode thickness, iodide concentration, dye structure and others. ${ }^{6-9}$

The average electron diffusion coefficients in anatase $\mathrm{TiO}_{2}$ ranges between $10^{-4}$ to $10^{-5}$ $\mathrm{cm}^{2} \cdot \mathrm{s}^{-1}{ }^{10}$, resulting in an electron transport time constant $\left(\tau_{t r}\right)$ for a typical $10 \mu \mathrm{m}$ thick photoelectrode in the range of few milliseconds. The electron lifetime $\left(\tau_{e-}\right)$ corresponding to a recombination reaction constant of $k_{5}$ - Figure 2, has the same order of magnitude of the electron transport time constant resulting in a directly competition between these two mechanisms. The current and potential outputs of the DSC are recombination limited, and result 
from a balance between the charge generation and the recombination fluxes. Controlling charge extraction, by increasing transport, and lowering charge recombination will increase the efficiency of DSCs. Thus, understanding charge recombination and controlling recombination rate constants is of utmost importance. Several studies have been carried out to understand how recombination can been lowered in DSCs, and many articles have been published examining the effect of electrolyte additives, new photoanode architectures, new dyes, surface coatings, among other factors ${ }^{11-23}$.

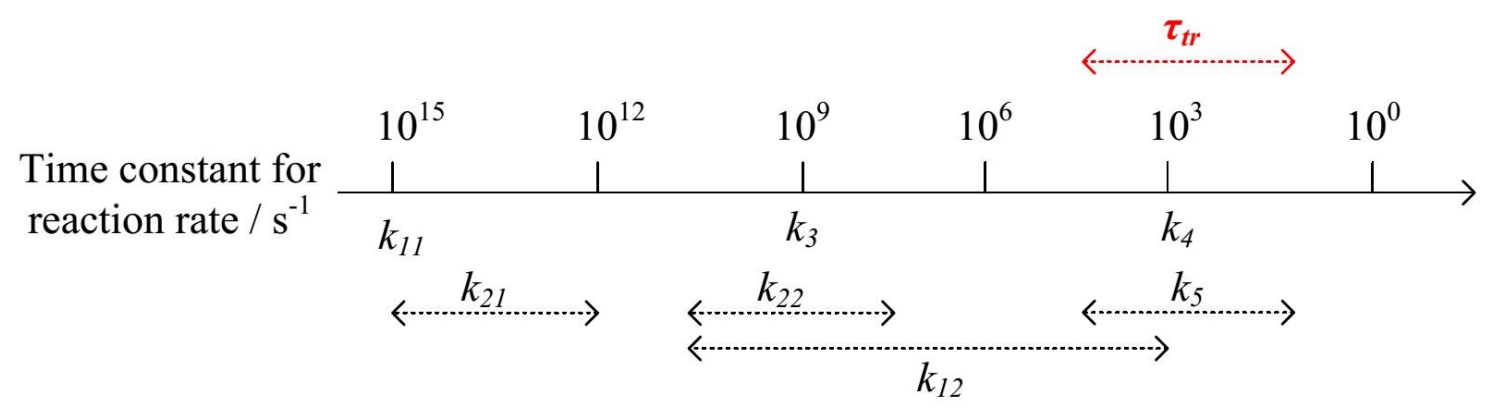

Fig. 2 Time constant ranges of the reactions in a DSC.

In this work a dynamic phenomenological model proposed initially by Andrade et al. ${ }^{24}$ is used to describe the quantitatively effect that transport and recombination have in the performance of the solar cell, and the influence that this has in its design. The model is used to predict the influence of the recombination reaction rate constants $\left(k_{r}\right)$ and diffusion coefficients $\left(D_{e f f}\right)$ in the $V_{o c}$ and $J_{s c}$, considering linear or non-linear recombination reaction. The results are helpful, particularly in decoupling phenomena seen in charge extraction experiments that are usually used to assess and compare recombination rates among DSC samples.

\section{Modeling}

The model used in this work is based on the initially proposed model by Andrade et al

${ }^{24}$ but taking into account the recombination reaction order parameter $\beta$. The mobile species considered in the present model are electrons in the conduction band of $\mathrm{TiO}_{2}$ and iodide and 
triiodide ions in the liquid electrolyte. The developed model of an irradiated DSC assumes the following physical and chemical processes:

1) electron generation (from excited dye molecules);

2) electron transport in the porous semiconductor $\left(\mathrm{TiO}_{2}\right)$;

3) electron recombination with electrolyte species;

4) oxidation of iodide (inside the pores of $\mathrm{TiO}_{2}$ );

5) and reduction of triiodide (at the platinum catalyst).

It is assumed that the cell is irradiated perpendicularly to the photoelectrode and that each absorbed photon generates one injected electron into the $\mathrm{TiO}_{2}$ conduction band. All injected electrons are considered from the excited state of the dye, and not from $\mathrm{TiO}_{2}$ band gap excitation. Reactions (1) and (2) are considered irreversible since their forward kinetic constants are much higher that the corresponding reverse kinetic constants $\left(k_{11} \gg k_{12} \text { and } k_{21} \gg k_{22}\right)^{5}$. Therefore only one possible mechanism for electron loss is assumed, corresponding to the recombination reaction of electrons with electrolyte species (5).

Figure 3 illustrates the modeled DSC. The photoelectrode is deposited over the TCO layer, which has an electrical resistance of $R_{\mathrm{TCO}}$, and is made of a film of sintered $\mathrm{TiO}_{2}$ nanoparticles with thickness $L_{f}$ and porosity $\varepsilon$. The dye is adsorbed on this mesoporous film of $\mathrm{TiO}_{2}$ as a monolayer. The dye has a wavelength-dependent light absorption coefficient of $\alpha(\lambda)$. The liquid electrolyte, made of the redox pair $\mathrm{I}^{-} / \mathrm{I}_{3}^{-}$(with diffusion coefficients $D_{\mathrm{I}^{-}}$and $D_{\mathrm{I}_{3}^{-}}$), is responsible for the regeneration of the dye, transporting low energy electrons from the counterelectrode. The $\mathrm{TCO}^{-\mathrm{TiO}_{2}}$ interface was defined to be at $x=0$. This interface is modeled as an ideal ohmic contact, meaning that there is no charge transfer resistance at the interface. At the counter electrode, the interface electrolyte-platinum catalyst happens at $x=L$ and the electrochemical reduction of $\mathrm{I}_{3}^{-}$was described by the Butler-Volmer equation. The electron transport in the photoelectrode was assumed to be governed by diffusion (negligible convection) 18 


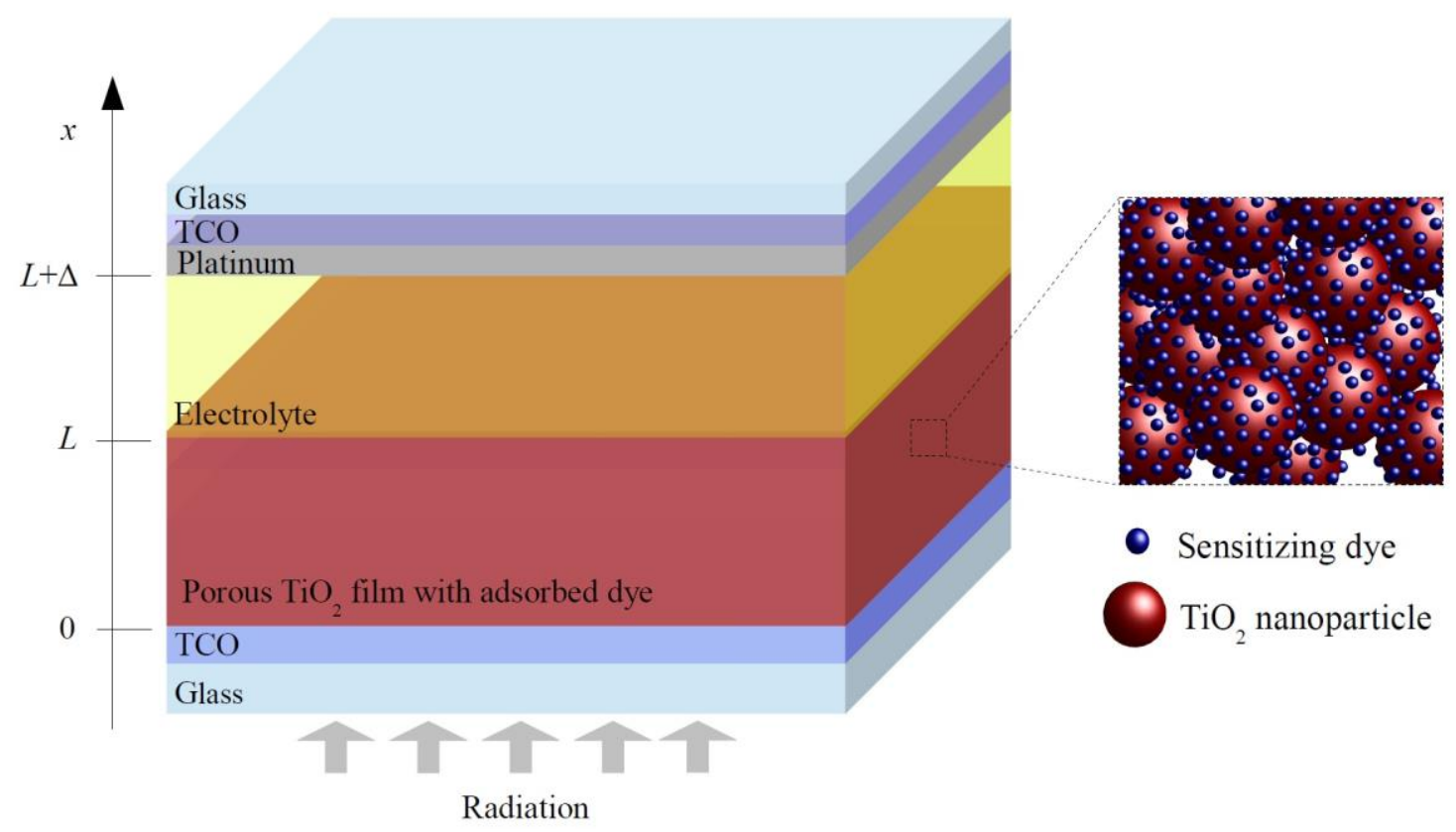

Fig. 3 Scheme of the modeled DSC.

From the previous assumptions, the continuity and transport equation that describe the mobile species is ${ }^{24}$ :

$$
-\frac{\partial J_{i}}{\partial x}+G_{i}(x)-R_{i}(x)=\frac{\partial n_{i}}{\partial t}, \quad i=\mathrm{e}^{-}, \mathrm{I}_{3}^{-}, \mathrm{I}^{-}
$$

The first term on the left hand side of equation (6) represents the charge carrier flux. The second and third terms, $G_{i}(x)$ and $R_{i}(x)$, represent the generation and recombination rates of species $i$, respectively. The term on the right hand side of the equation is the concentration species $i$ time derivative. The charge carrier flux, $J_{i}$, is assumed to occur by diffusion only and is given by the Fick's law ${ }^{25}$ :

$$
J_{i}=-D_{i} \frac{\partial n_{i}}{\partial x}
$$

and the generation rate is given by the Beer-Lambert law that relates the absorption of light to the properties of the material through which the light is travelling:

$$
G_{i}=\eta_{\text {inj }} \alpha(\lambda) I_{0} e^{-\alpha(\lambda) x}
$$

Each absorbed photon is assumed to produce one injected electron. The developed model considers a uniformly distributed monolayer of dye through the surface area of $\mathrm{TiO}_{2}$. The injection efficiency parameter, $\eta_{\text {inj }}$, takes into account this phenomenon but also the light reflection and glass and electrolyte absorption losses. 
For each two electrons that react with triiodide, three ions of iodide are formed (reaction 5). The recombination rate term can be written as follows ${ }^{26}$ :

$$
R_{\mathrm{e}^{-}}=k_{r}\left(n_{\mathrm{e}^{-}}(x, t)-n_{\mathrm{eq}}\right)^{\beta}
$$

The recombination reaction kinetics is subject of much debate and some of the scientific work published so far considers that this reaction follows first-order kinetics:

$$
\beta=1 ; k_{r}=\frac{1}{\tau_{\mathrm{e}^{-}}}
$$

where $k_{r}$ is the reacton rate constant and $\tau_{\mathrm{e}^{-}}$is the electron lifetime.

However, several uncertainties surround the recombination kinetics in DSCs and the respective parameters that govern the solar cells behavior. Some models assume that the rate at which electrons are transferred from the conduction band to the redox electrolyte is first order in free electron concentration $(\beta=1)^{27,28}$. However, it has been suggested that deviations from the first order model may arise from the recombination process being mediated by electronic surface states below the $\mathrm{TiO}_{2}$ conduction band ${ }^{29-31}$. A non-linear model formulation has then being suggested:

$$
\beta \neq 1 ; k_{r}=k_{0} \frac{1}{\tau_{\mathrm{e}^{-}}}
$$

where $k_{r}$ is the reaction rate constant and $k_{0}$ is a model constant. The driving force of the recombination reaction is the diference between the generated electrons density, $n_{\mathrm{e}^{-}}(x, t)$, and the dark equilibrium electron density, $n_{\text {eq }}$. This electron density corresponds to the resulting equilibrium bewteen the electron at the fermi level and the redox potential of the electrolyte:

$$
n_{\mathrm{eq}}=N_{\mathrm{CB}} \exp \left[-\frac{E_{\mathrm{CB}}-E_{\mathrm{redox}}}{\mathrm{k}_{\mathrm{B}} T}\right]
$$

According to the above assumptions the model equations can be written as follows:

\section{Electrons balance}

Introducing equations (7), (8), and (9) into the continuity equation (6), the continuity equation for electrons comes:

$$
D_{\mathrm{e}^{-}} \frac{\partial^{2} n_{\mathrm{e}^{-}}}{\partial x^{2}}+\eta_{\mathrm{inj}} \alpha(\lambda) I_{0} e^{-\alpha(\lambda) x}-k_{r}\left(n_{\mathrm{e}^{-}}(x, t)-n_{\mathrm{eq}}\right)^{\beta}=\frac{\partial n_{\mathrm{e}^{-}}}{\partial t}
$$


Assuming that for $t=0$ the cell is not illuminated, the electron density is equal to the dark electron density, $n_{\text {eq }}$ :

$$
t=0 \quad n_{\mathrm{e}^{-}}(x, 0)=n_{\mathrm{eq}}
$$

A charge balance at the interface $x=0$ determines that the electron flux at $x=0^{+}$equals the electron flux at $x=0^{-}$. Therefore, the charge balance at this interface is given by $J_{\mathrm{e}^{-}}^{0^{+}}=J_{\mathrm{e}^{-}}^{0^{-}}$. Because $J_{\mathrm{e}^{-}}^{0^{+}}$corresponds to the diffusive electrons transported through the $\mathrm{TiO}_{2}$, which in steady state is the net current produced by the solar cell, $J_{\text {cell }}$, the boundary condition for $x=0$ is:

$$
x=0 ; J_{\mathrm{e}^{-}}^{0^{+}}=-\left.\mathrm{q} D_{\mathrm{e}^{-}} \frac{\partial \mathrm{n}_{\mathrm{e}^{-}}}{\partial \mathrm{x}}\right|_{x=0^{+}}
$$

At $x=L$ there is no contact between the film of $\mathrm{TiO}_{2}$ nanoparticles and the platinized FTO. Therefore, there are no electrons bridging between the photoelectrode and the couterelectrode. Only iodide and triiodide perform this charge transfer. Thus, the corresponding boundary condition for $x=L$ is:

$$
x=L ; \frac{\partial n_{\mathrm{e}^{-}}}{\partial x}=0
$$

\section{Iodide and Triiodide balance}

Each generated mole of electrons causes the consumption of one mole of $\mathrm{I}^{-}$ion and the production of half mole of $\mathrm{I}_{3}{ }^{-}$that can be reduced back to $\mathrm{I}^{-}$form either at the platinum layer or due to the recombination reaction (undesirable back reaction). Besides the reduction of triiodide that takes place at the counter-electrode, the oxidation and reduction reactions of the ionic species take place in the photoelectrode porosity. Accordingly to the stoichiometry reactions (3) and (4) the terms of generation and recombination of triiodide and iodide must be affected by the corresponding coefficients:

$$
\begin{aligned}
& D_{\mathrm{I}^{-}} \frac{\partial^{2} n_{\mathrm{I}^{-}}}{\partial x^{2}}-\frac{3}{2 \varepsilon_{p}}\left[\eta_{\mathrm{inj}} \alpha(\lambda) I_{0} e^{-\alpha(\lambda) x}-k_{r}\left(n_{\mathrm{e}^{-}}(x, t)-n_{\mathrm{eq}}\right)^{\beta}-\frac{\partial n_{\mathrm{e}^{-}(x, t)}}{\partial t}\right]=\frac{\partial n_{\mathrm{I}^{-}}(x, t)}{\partial t} \\
& D_{\mathrm{I}_{3}^{-}} \frac{\partial^{2} n_{\mathrm{I}_{3}^{-}}}{\partial x^{2}}+\frac{1}{2 \varepsilon_{p}}\left[\eta_{\mathrm{inj}} \alpha(\lambda) I_{0} e^{-\alpha(\lambda) x}-k_{r}\left(n_{\mathrm{e}^{-}}(x, t)-n_{\mathrm{eq}}\right)^{\beta}-\frac{\partial n_{\mathrm{e}^{-}(x, t)}}{\partial t}\right]=\frac{\partial n_{\mathrm{I}_{3}^{-}}(x, t)}{\partial t}
\end{aligned}
$$

At instant $t=0$, the concentration of iodide and triiodide is known: 


$$
t=0: n_{\mathrm{I}_{3}^{-}}(x, 0)=n_{\mathrm{I}_{3}^{-}}^{\mathrm{ini}} ; n_{\mathrm{I}^{-}}(x, 0)=n_{\mathrm{I}^{-}}^{\mathrm{ini}}
$$

At the interface of $\mathrm{TiO}_{2} / \mathrm{TCO}, x=0$, only electrons are able to flow so the net flux of $\mathrm{I}_{3}^{-}$and $\mathrm{I}^{-}$is zero:

$$
x=0: \frac{\partial n_{\mathrm{I}_{3}^{-}}}{\partial x}=0 ; \frac{\partial n_{\mathrm{I}^{-}}}{\partial x}=0
$$

Although there is generation and consumption of both ionic species, their total number of moles remains constant, thus resulting in the following integral boundary condition:

$$
x=L: \int_{0}^{L} n_{\mathrm{I}_{3}^{-}}(x) d x=n_{\mathrm{I}_{3}^{-}}^{\mathrm{ini}} L ; \int_{0}^{L} n_{\mathrm{I}^{-}}(x) d x=n_{\mathrm{I}^{-}}^{\mathrm{ini}} L
$$

For the three charged species, $\mathrm{e}^{-}, \mathrm{I}_{3}^{-}$and $\mathrm{I}^{-}$, the initial and boundary conditions, (14), (16), (17) and (21)-(23), are given and are necessary to solve the three non-linear differential equation system, (13), (18) and (19). However, additional information is needed at $x=0$ to solve the system: the net current at this interface must be known, $J_{\text {cell }}$. Assuming that the external circuit has no resistances, the electron density generated by the cell, $J_{\text {cell }}$, equals the current density that is returned to the cell via the counter electrode, $J_{0}$. Here, electrons participate in the reduction reaction of triiodide to iodide - reaction (4) - catalyzed by the platinum catalyst deposited on top of the TCO surface and thus it can be treated as an electrochemical half-cell ${ }^{32}$; the charge transfer can be described by the Butler-Volmer equation. This approach is considered to describe the electrochemical kinetics at this interface $x=L+\Delta{ }^{33}$, ${ }^{34}$ :

$$
j_{\text {cell }}=j_{0}\left[\frac{n_{\mathrm{I}_{3}^{-}}(L)}{n_{\mathrm{I}_{3}^{-}}^{\mathrm{oC}}(L)} e^{\frac{\alpha q \eta_{\mathrm{Pt}}}{k_{B} T}}-\frac{n_{\mathrm{I}^{-}}(L)}{n_{\mathrm{I}^{-}}^{\mathrm{oC}}(L)} e^{\frac{-(1-\alpha) q \eta_{\mathrm{Pt}}}{k_{B} T}}\right]
$$

The Butler-Volmer equation describes the reduction reaction overpotential at the counter-electrode catalyst as a function of the current density. It describes the charge transfer over a metal/electrolyte interface assuming no charge diffusion limitations in the electrolyte. The charge transfer reaction at the platinized interface has a charge transfer resistance, $R_{c t}$. An overpotential is necessary to drive the reaction at a certain current density, $J_{\text {cell }}$. As stated by 
equation (24), the current density of the cell depends on the exchange current density, $J_{0,}$, which is the electron's ability to exchange with the solution, but also with the platinum overpotential, $\eta_{P t}$. This value translates the necessary potential to overcome the energy barrier of the reaction of the electrons with the triiodide. This corresponds to an overall potential loss of the solar cell and must be as low as possible ${ }^{35,36}$. The counter electrode overpotential, $\eta_{P t}$, can be obtained as follows: ${ }^{24}$

$$
\begin{gathered}
\Delta V_{\mathrm{int}}=\frac{1}{q}\left[E_{\mathrm{CB}}+k_{B} T \ln \frac{n_{\mathrm{e}^{-}(x=0)}}{N_{\mathrm{CB}}}-E_{\mathrm{redox}}^{0}-\frac{k_{B} T}{2} \ln \frac{n_{\mathrm{I}_{3}^{\mathrm{c}}}^{\mathrm{oc}}}{\left(n_{\mathrm{I}^{-}}^{\mathrm{oc}} L\right)^{3}}-q \eta_{\mathrm{Pt}}\right] \Leftrightarrow \\
\eta_{\mathrm{Pt}}=\frac{E_{\mathrm{CB}}-E_{\mathrm{redox}}^{\mathrm{oc}}}{q}+\frac{k_{B} T}{q}\left[\ln \frac{n_{\mathrm{I}_{3}^{\circ}}^{\mathrm{oc}}}{2\left(n_{\mathrm{I}^{-}}^{\mathrm{oc}} L\right)^{3}}+\ln \frac{n_{\mathrm{e}^{-}(x=0)}}{N_{\mathrm{CB}}}\right]-\Delta V_{\mathrm{int}}
\end{gathered}
$$

Analyzing equation (33) is understood that $\eta_{P t}$, and consequently the electrons flux, depends on the internal potential of the solar cell. There are also external resistances that should be accounted for and correlated to the internal resistances; this can be done using Kirchhoff's and Ohm's laws ${ }^{32}$ :

$$
\Delta V_{\text {int }}=\left(R_{\text {series }}+R_{\text {ext }}\right)\left(\frac{R_{p}}{R_{\text {ext }}+R_{\text {series }}+R_{p}}\right) A J_{\text {cell }}
$$

where $R_{\text {series }}$ is the sum of all external resistances, $R_{e x t}$ is the applied load, $R_{p}$ are the shunt resistances, and $A$ the active area of the DSC. Equation (34) should be inserted in counter electrode overpotential equation (33) and then introduced in the Butler-Volmer equation (24). Thus the produced current of the solar cell, equation (24), can be determined by the applied load, $R_{\text {ext }}$. The external potential given by the device is calculated taking into account the produced current, the applied load and the other resistances taken into account in the model:

$$
V_{\text {ext }}=R_{\text {ext }}\left(\frac{R_{p}}{R_{\text {ext }}+R_{\text {series }}+R_{p}}\right) A J_{\text {cell }}
$$

To decrease the number of variables and to improve numerical convergence issues of the numerical methods, the model parameters were made dimensionless respecting to the electron and ionic species parameters and the semiconductor thickness: 


$$
\begin{aligned}
& \gamma=\alpha(\lambda) L, \quad \theta=\frac{D_{\mathrm{ref}}}{L^{2}} t, \quad n_{i}^{*}=\frac{n_{i}}{n_{\mathrm{ref}}}, \quad x^{*}=\frac{x}{L}, \\
& D_{i}^{*}=\frac{D_{i}}{D_{\text {ref }}}, \quad j_{\text {cell }}^{*}=\frac{j_{\text {cell }}}{j_{0}}, \quad D a=\frac{L^{2} \eta_{\text {inj }} \alpha(\lambda) I_{0}}{D_{\text {ref }} n_{\text {ref }}}, \quad \phi=L \sqrt{\frac{k_{r}}{D_{\text {ref }}}}
\end{aligned}
$$

Using the above established dimensionless variables, the dimensionless equations and respective initial and boundary conditions can be written as follows for the three modeled species $\left(\mathrm{e}^{-}, \mathrm{I}_{3}^{-}\right.$and $\left.\mathrm{I}^{-}\right)$:

\section{Dimensionless Electrons Balance}

$$
D_{\mathrm{e}^{-}}^{*} \frac{\partial n_{\mathrm{e}^{-}}^{*}}{\partial x^{* 2}}+\left[D a e^{-\gamma x^{*}}-\phi^{2}\left(n_{\mathrm{e}^{-}}^{*}-n_{\mathrm{eq}}^{*}\right)^{\beta}\right]=\frac{\partial n_{\mathrm{e}^{-}}^{*}}{\partial \theta}
$$

Initial condition:

$$
\theta=0 ; n_{\mathrm{e}^{-}}^{*}\left(x^{*}, 0\right)=n_{\mathrm{eq}}^{*}
$$

Boundary conditions:

$$
x^{*}=0 ; J_{\text {cell }}^{*}=\frac{n_{\text {ref }} D_{\text {ref }} q}{L}\left(\left.D_{\mathrm{e}^{-}} \frac{\partial n_{\mathrm{e}^{-}}^{*}}{\partial x^{*}}\right|_{x=0^{+}}\right) ; x^{*}=1 ; \frac{\partial n_{\mathrm{e}^{-}}^{*}}{\partial x^{*}}=0
$$

\section{Dimensionless Triiodide Balance}

$$
D_{\mathrm{I}_{3}^{-}}^{*} \frac{\partial^{2} n_{\mathrm{I}_{3}^{-}}^{*}}{\partial x^{* 2}}+\frac{1}{2 \varepsilon_{p}}\left[D a e^{-\gamma x^{*}}-\phi^{2}\left(n_{\mathrm{e}^{-}}^{*}-n_{\mathrm{eq}}^{*}\right)^{\beta}-\frac{\partial n_{\mathrm{e}^{-}}^{*}}{\partial \theta}\right]=\frac{\partial n_{\mathrm{I}_{3}^{-}}^{*}}{\partial \theta}
$$

Initial condition:

$$
\theta=0 ; n_{\mathrm{I}_{3}^{-}}^{*}\left(x^{*}, 0\right)=n_{\mathrm{I}_{3}^{-}}^{* i n i}
$$

Boundary conditions:

$$
x^{*}=0 ; \frac{\partial n_{\mathrm{I}_{3}^{-}}^{*}(0, \theta)}{\partial x^{*}}=0 ; x^{*}=1 ; \int_{0}^{1} n_{\mathrm{I}_{3}^{-}}^{*}\left(x^{*}\right) d x^{*}=n_{\mathrm{I}_{3}^{*}}^{* i n i}
$$

\section{Dimensionless Iodide Balance}




$$
\mathrm{D}_{\mathrm{I}^{-}}^{*} \frac{\partial^{2} \mathrm{n}_{\mathrm{I}^{-}}}{\partial \mathrm{x}^{* 2}}-\frac{3}{2 \varepsilon_{\mathrm{p}}}\left[\mathrm{Da} \cdot \mathrm{e}^{-\gamma \mathrm{x}^{*}}-\phi^{2}\left(\mathrm{n}_{\mathrm{e}^{-}}^{*}-\mathrm{n}_{\mathrm{eq}}^{*}\right)^{\beta}-\frac{\partial \mathrm{n}_{\mathrm{e}^{-}}^{*}}{\partial \theta}\right]=\frac{\partial \mathrm{n}_{\mathrm{I}^{-}}^{*}}{\partial \theta}
$$

Initial condition:

$$
\theta=0 ; n_{\mathrm{I}^{-}}^{*}\left(x^{*}, 0\right)=n_{\mathrm{I}^{-}}^{* \text { ini }}
$$

\section{Boundary conditions:}

$$
x^{*}=0 ; \frac{\partial n_{\mathrm{I}^{-}}^{*}(0, \theta)}{\partial x^{*}}=0 ; x^{*}=1 ; \int_{0}^{1} n_{\mathrm{I}^{-}}^{*}\left(x^{*}\right) d x^{*}=n_{\mathrm{I}^{-}}^{* \text { ini }}
$$

The system of equations (36), (39) and (42) describes the history of the mobile species concentration profiles. The partial differential equations were spatially discretized using the finite differences method. The time integration was accomplished by the numerical package developed by the Lawrence Livermore National Laboratory, LSODA ${ }^{37}$.

\section{Experimental}

\section{Dye sensitized solar cell preparation}

Steady state simulated results were critically compared with experimental results of two DSCs with different photoelectrode thicknesses: device A with $7.5 \mu \mathrm{m}$ and device B with $12.5 \mu \mathrm{m}$. The photoelectrodes were prepared on $2.2 \mathrm{~mm}$ thick and $7 \Omega / \square$ FTO coated glass substrates from Solaronix ${ }^{\circledR}$. First, the glasses were washed sequentially with a detergent solution (Alconox ${ }^{\circledR}, \mathrm{VWR}$ ) in an ultrasonic bath at $55^{\circ} \mathrm{C}$ for $15 \mathrm{~min}$, followed by ultrasonic cleaning in deionized water at room temperature, rinsed with ethanol and dried with air. To form a thin and compact layer of $\mathrm{TiO}_{2}$ above the FTO layer, the substrates were immersed in a $40 \mathrm{mM} \mathrm{TiCl} l_{4}$ aqueous solution at $70^{\circ} \mathrm{C}$, for 20 minutes. After washing with water and ethanol, the samples were dried with a nitrogen flow. Then, the samples were coated with porous $\mathrm{TiO}_{2}$ layer by screen printing a commercial $\mathrm{TiO}_{2}$ paste (Ti-Nanoxide T/SP from Solaronix ${ }^{\circledR}$ ), followed by drying at $80{ }^{\circ} \mathrm{C}$ for 20 minutes. To control the final thickness of the transparent layer of $\mathrm{TiO}_{2}$, the screen printing procedure (printing and drying) was repeated as necessary to 
get the desired thickness of photoelectrode. The samples were annealed at $500{ }^{\circ} \mathrm{C}$ for $15 \mathrm{~min}$ in an infrared electrical oven. After firing, the samples were again treated with a $40 \mathrm{mM} \mathrm{TiCl}$ aqueous solution at $70{ }^{\circ} \mathrm{C}$ for 20 minutes, before being sintered at $500{ }^{\circ} \mathrm{C}$ for $30 \mathrm{~min}$. The counter electrodes, prepared on the same type of glass substrates and cleaned as described before, were drilled previously with two holes of $1 \mathrm{~mm}$ diameter. A drop of $\mathrm{H}_{2} \mathrm{PtCl}_{6}$ solution (2 $\mathrm{mg}$ of Pt in $1 \mathrm{~mL}$ ethanol) was applied on the glass substrate followed by annealing at $400{ }^{\circ} \mathrm{C}$ for 15 minutes. Both electrodes were assembled and sealed using a laser assisted glass frit method described elsewhere ${ }^{38}$. Dye adsorption in the porous $\mathrm{TiO}_{2}$ was obtained recirculating 1 mM N719 dye solution for 10 hours, followed by ethanol rinsing, nitrogen drying, electrolyte filling (Iodolyte Z-150 from Solaronix®) and hole sealing by thermoplastic sealant (Surlyn®, Dupont).

\section{Results and Discussion}

\section{Current-Potential Characteristics}

The input values of parameters for the simulation step are listed in Table 1. For each parameter it is indicated if the value was obtained by fitting to the experimental results (parameters $k_{r}, \beta$ and $E_{c}-E_{\text {redox }}$ ) or from an independent source.

The experimental $I-V$ characteristics were obtained in a set-up equipped with a $1600 \mathrm{~W}$ xenon light source (Oriel class B solar simulator, Newport, USA) irradiating $100 \mathrm{~mW} \cdot \mathrm{cm}^{-2}(1$ sun light intensity) and using a 1.5 air mass filter (Newport, USA). The simulator was calibrated using a single crystal Si photodiode (Newport, USA). The $I-V$ characteristics of the solar cell were obtained applying an external potential bias (electrical load) and measuring the generated photocurrent. 
Table 1. Input values for the simulation step for device A and B.

\begin{tabular}{|c|c|c|c|c|c|}
\hline & Parameter & notation & Device A & Device B & Ref \\
\hline \multirow{3}{*}{$\begin{array}{l}\text { Morphological } \\
\text { features }\end{array}$} & Cell Thickness & $L / \mu \mathrm{m}$ & 7.5 & 12.5 & Measured \\
\hline & Film Porosity & $\varepsilon$ & \multicolumn{2}{|c|}{0.63} & Computed \\
\hline & Active area & $A / \mathrm{cm}^{2}$ & \multicolumn{2}{|c|}{0.158} & Measured \\
\hline \multirow{4}{*}{$\begin{array}{l}\text { Photon } \\
\text { absorption/ } \\
\text { electron } \\
\text { Injection }\end{array}$} & Incident Photon Flux & $I_{s} / \mathrm{cm}^{-2 \cdot} \mathrm{s}^{-1}$ & \multicolumn{2}{|c|}{$1.47 \times 10^{17}$} & Measured \\
\hline & Injection Efficiency & $\eta_{i n j}$ & \multicolumn{2}{|c|}{0.90} & 39 \\
\hline & $\begin{array}{c}\text { Dye Absorption } \\
\text { Coefficient }\end{array}$ & $\alpha(\lambda) / \mathrm{cm}^{-1}$ & \multicolumn{2}{|c|}{1000} & Computed \\
\hline & Temperature & $T / \mathrm{K}$ & \multicolumn{2}{|c|}{298} & Measured \\
\hline \multirow{5}{*}{$\begin{array}{l}\text { Initial/boundary } \\
\text { concentrations } \\
\text { of species }\end{array}$} & \multirow{3}{*}{$\begin{array}{c}\text { Initial } \\
\text { Concentrations }\end{array}$} & $\mathrm{C}_{\mathrm{e}-}^{0}$ & \multicolumn{2}{|c|}{0} & - \\
\hline & & $C_{I_{3}^{-}}^{0} / \mathrm{mmol} \cdot \mathrm{dm}^{-3}$ & \multicolumn{2}{|c|}{100.0} & Computed \\
\hline & & $C_{I^{-}}^{0} / \mathrm{mmol} \cdot \mathrm{dm}^{-3}$ & \multicolumn{2}{|c|}{1100} & Computed \\
\hline & \multirow{2}{*}{$\begin{array}{l}\text { Open-Circuit } \\
\text { Concentrations }\end{array}$} & $C_{I_{3}^{-}}^{o c} / \mathrm{mmol} \cdot \mathrm{dm}^{-3}$ & \multicolumn{2}{|c|}{99.00} & Computed \\
\hline & & $C_{I^{-}}^{o c} / \mathrm{mmol} \cdot \mathrm{dm}^{-3}$ & \multicolumn{2}{|c|}{1102} & Computed \\
\hline \multirow{3}{*}{$\begin{array}{c}\text { Diffusion } \\
\text { coefficients of } \\
\text { species }\end{array}$} & \multirow{3}{*}{$\begin{array}{l}\text { Diffusion } \\
\text { coefficients }\end{array}$} & $D_{I_{3}^{-}} / \mathrm{cm}^{2} \cdot \mathrm{s}^{-1}$ & \multicolumn{2}{|c|}{$4.91 \times 10^{-6}$} & 24 \\
\hline & & $D_{I^{-}} / \mathrm{cm}^{2} \cdot \mathrm{s}^{-1}$ & \multicolumn{2}{|c|}{$4.91 \times 10^{-6}$} & 24 \\
\hline & & $D_{e f f} / \mathrm{cm}^{2} \cdot \mathrm{s}^{-1}$ & \multicolumn{2}{|c|}{$1.10 \times 10^{-4}$} & 24 \\
\hline \multirow{2}{*}{$\begin{array}{l}\text { Pt Counter } \\
\text { electrode }\end{array}$} & $\begin{array}{l}\text { Exchange Current } \\
\text { Density }\end{array}$ & $j_{0} / \mathrm{mA} \cdot \mathrm{cm}^{-2}$ & \multicolumn{2}{|c|}{$6.81 \times 10^{-2}$} & Computed \\
\hline & $\begin{array}{l}\text { Symmetry } \\
\text { Parameter }\end{array}$ & $\alpha$ & \multicolumn{2}{|c|}{0.78} & 32 \\
\hline \multirow{2}{*}{$\begin{array}{l}\text { Recombination } \\
\text { reaction }\end{array}$} & $\begin{array}{l}\text { Reaction order } \\
\text { coefficient }\end{array}$ & $\beta$ & \multicolumn{2}{|c|}{0.75} & Fit \\
\hline & Rate constant & $k_{r} / \mathrm{m}^{-0.75} \cdot \mathrm{s}^{-1}$ & 8.00 & 6.62 & Fit \\
\hline \multirow[b]{2}{*}{$\begin{array}{l}\text { Density of } \\
\text { States }\end{array}$} & $E_{c b}-E_{r e d o x}$ & $\mathrm{eV}$ & 0.93 & 0.94 & Fit \\
\hline & $\begin{array}{l}\text { Effective density of } \\
\text { states in the } \mathrm{TiO}_{2} \\
\text { conduction band }\end{array}$ & $N_{c} / \mathrm{cm}^{-3}$ & \multicolumn{2}{|c|}{$1.00 \times 10^{21}$} & 40 \\
\hline \multirow{2}{*}{$\begin{array}{c}\text { External } \\
\text { Resistances }\end{array}$} & Shunt Resistances & $R_{p} / \Omega$ & 76129 & 14392 & Computed \\
\hline & $\begin{array}{l}\text { External Series } \\
\text { resistances }\end{array}$ & $R_{\text {series }} / \Omega$ & 40 & 47 & Computed \\
\hline
\end{tabular}

Figure 4 plots the experimental and simulated $I-V$ and power curves for the two sets of samples. The experimental and simulated results are in good agreement. Table 2 present the experimental and simulated performance parameters; the relative different between both is smaller than $2 \%$ giving showing that the model is able to simulate accurately the experimental results. 


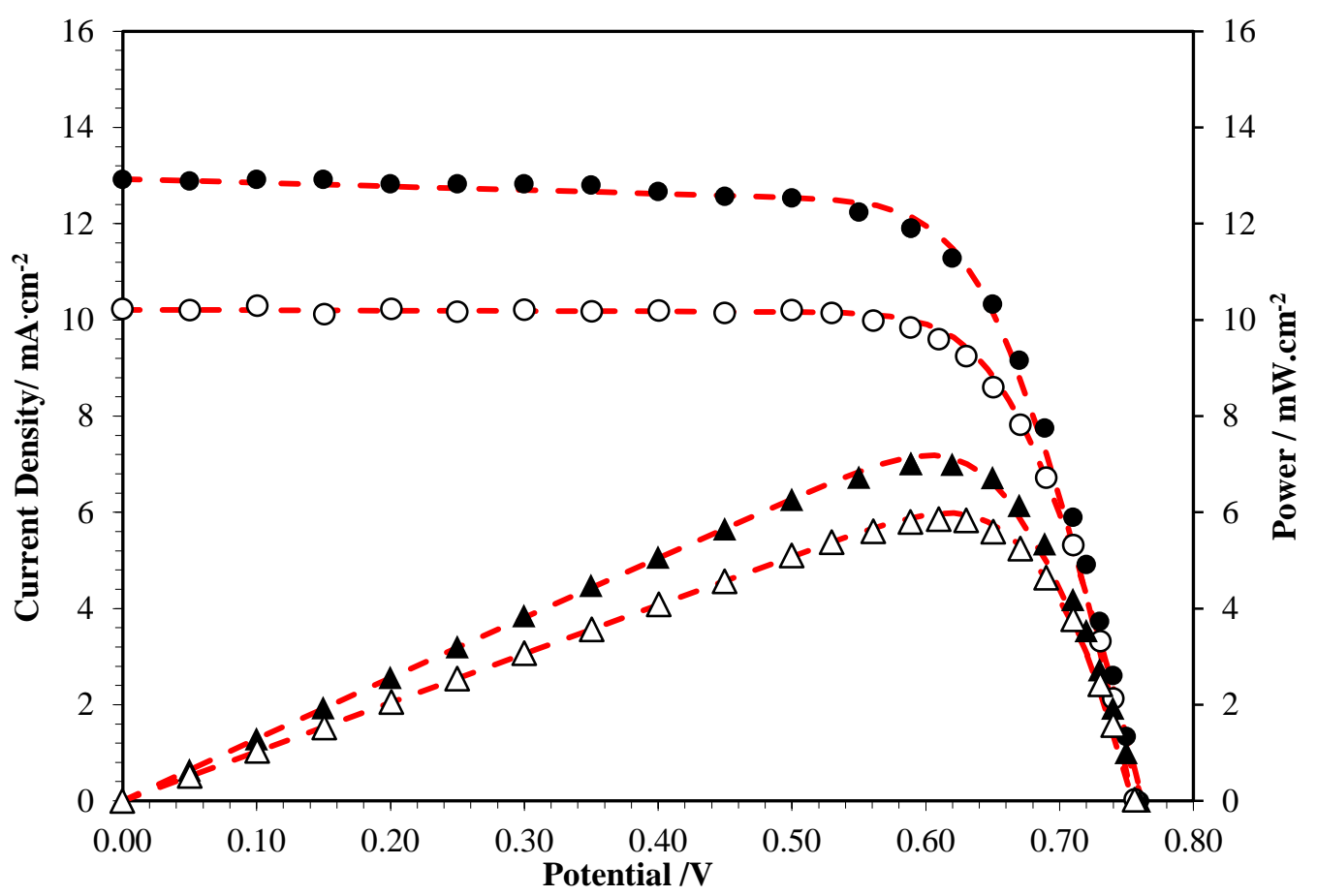

- Experimental I-V, device B O Experimental I-V, device A

- Experimental power curve, device B $\Delta$ Experimental power curve, device A - - Model

Fig. 4 Experimental and simulated results $I-V$ and power curves for device A and B (photoelectrode with $7.5 \mu \mathrm{m}$ and $12.5 \mu \mathrm{m}$ thickness). All other parameters are presented in Table 1.

Table 2. Performance parameters of the simulated and experimental results.

\begin{tabular}{ccccccc}
\hline $\begin{array}{c}\text { Semiconductor } \\
\text { thickness }\end{array}$ & \multicolumn{5}{c}{$12.5 \mu \mathrm{m}$} & \multicolumn{3}{c}{$7.5 \mu \mathrm{m}$} \\
\hline $\begin{array}{c}\text { Performance } \\
\text { Parameter }\end{array}$ & Simulation & Experimental & (Error \%) & Simulation & Experimental & (Error \%) \\
\hline $\begin{array}{c}J_{s c} / \mathrm{mA} \cdot \mathrm{cm}^{-2} \\
V_{o c} / \mathrm{V}\end{array}$ & 12.93 & 12.95 & $(0.1)$ & 10.21 & 10.23 & $(0.2)$ \\
$\mathrm{Max} . \mathrm{PP}$ & 0.75 & 0.76 & $(0.6)$ & 0.76 & 0.76 & $(0.7)$ \\
$/ \mathrm{mW} \cdot \mathrm{cm}^{-2}$ & 7.18 & 7.12 & $(0.9)$ & 5.98 & 5.88 & $(1.7)$ \\
$V_{m p p} / \mathrm{V}$ & 0.61 & 0.60 & $(1.2)$ & 0.62 & 0.62 & $(0.0)$ \\
$J_{m p p} / \mathrm{mA} \cdot \mathrm{cm}^{-2}$ & 11.85 & 11.89 & $(0.1)$ & 9.63 & 9.48 & $(1.6)$ \\
Fill Factor & 0.74 & 0.73 & $(1.4)$ & 0.77 & 0.76 & $(1.2)$ \\
Efficiency, $\eta$ & $\mathbf{7 . 1 8}$ & $\mathbf{7 . 1 2}$ & $(0.9)$ & $\mathbf{5 . 9 8}$ & $\mathbf{5 . 8 8}$ & $(1.7)$ \\
\hline
\end{tabular}


Even though the model predicts the experimental results reasonably well, there are some deviations, particularly in the maximum power point. The deviation is caused by the difference in the simulated and experimental fill factor. This difference probably relates to the rough estimation made for the shunt resistance. The shunt resistance relates to the back electron transfer across the $\mathrm{TiO}_{2} /$ dye/electrolyte interface, particularly in the dye free areas of the $\mathrm{TiO}_{2}$ surface and can be estimated from the slope of the experimental $I-V$ curve at short circuit. ${ }^{41}$

\section{Influence of recombination in DSCs}

Controlling the recombination reaction is believed to be the key to developing new materials and cell architectures for high efficient DSCs. Thus the interpretation of the recombination rate constants influence in the working mechanisms of DSCs is of extreme

importance. ${ }^{40,42}$. In the previous section the model was compared to experimental results and proved to model well the steady state behavior of the prepared DSCs. In this section, the influence of $k_{r}$ in the performance of the solar cell is assessed. This parameter affects the amount of generated electrons that react back to the electrolyte. Figure 5 shows the simulated $I$ $V$ curves for recombination rate constants ranging from 5 to $1000 \mathrm{~s}^{-1}(\beta=1)$. Clearly, the $I-V$ curve is affected by the amount of electrons that recombine, which is reflected particularly in the $J_{s c}$ and $V_{o c}$ values. 


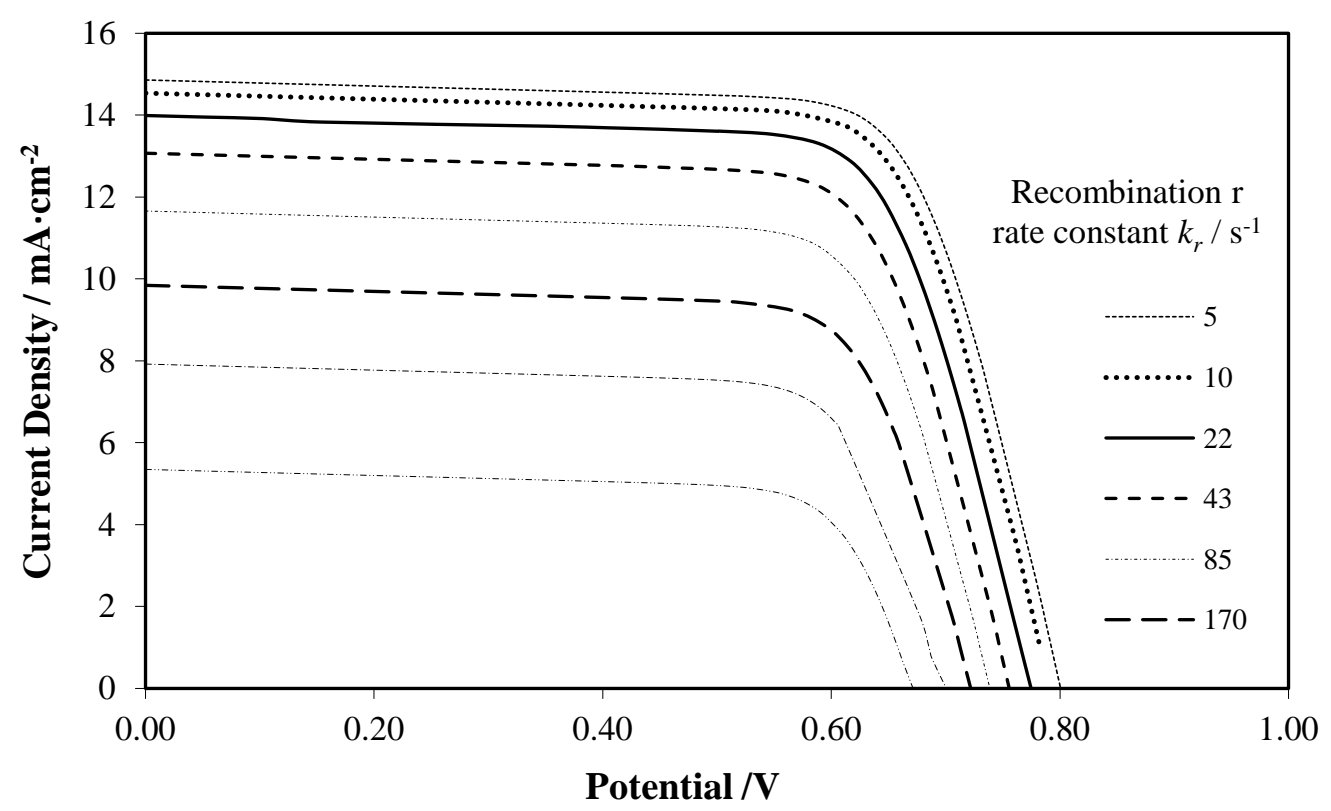

Fig. 5 Simulated $I$ - $V$ curves with different recombination reaction rate constants. All other parameters are presented in Table 1, device B.

Figure 6 shows the simulated electron density profiles at steady-state conditions and the theoretical photon absorption/electron generation through the $\mathrm{TiO}_{2}$ film according to the BeerLambert law. Since solar radiation is assumed to strike the photoanode side of the solar cell (see Figure 3), at $x=0$, most of the electrons are generated near this interface, due to the exponential behavior of the absorption law. For this reason, and also because the transport path for the generated electrons increases from $x=0$ to $12.5 \mu \mathrm{m}$, a larger electron density gradient is seen at the beginning of the film decreasing towards zero at positions close to $x=12.5 \mu \mathrm{m}$. This indicates that the initial $\mathrm{TiO}_{2}$ layer thickness fraction closer to the illuminated side of the solar cell is the one that contribute the most for the current delivered by the cell. The change in the electron lifetime (assumed first order recombination) has a strong influence in the electron density across the semiconductor. The electron density profiles have been simulated for shortcircuit (Figure 6), maximum power point (Figure 7) and open circuit conditions (Figure 8). As expected, for higher recombination rates the concentration of electrons are lower justifying the lower values of $J_{s c}$ (Figure 6) and $V_{o c}$ (Figure 8) parameters. 


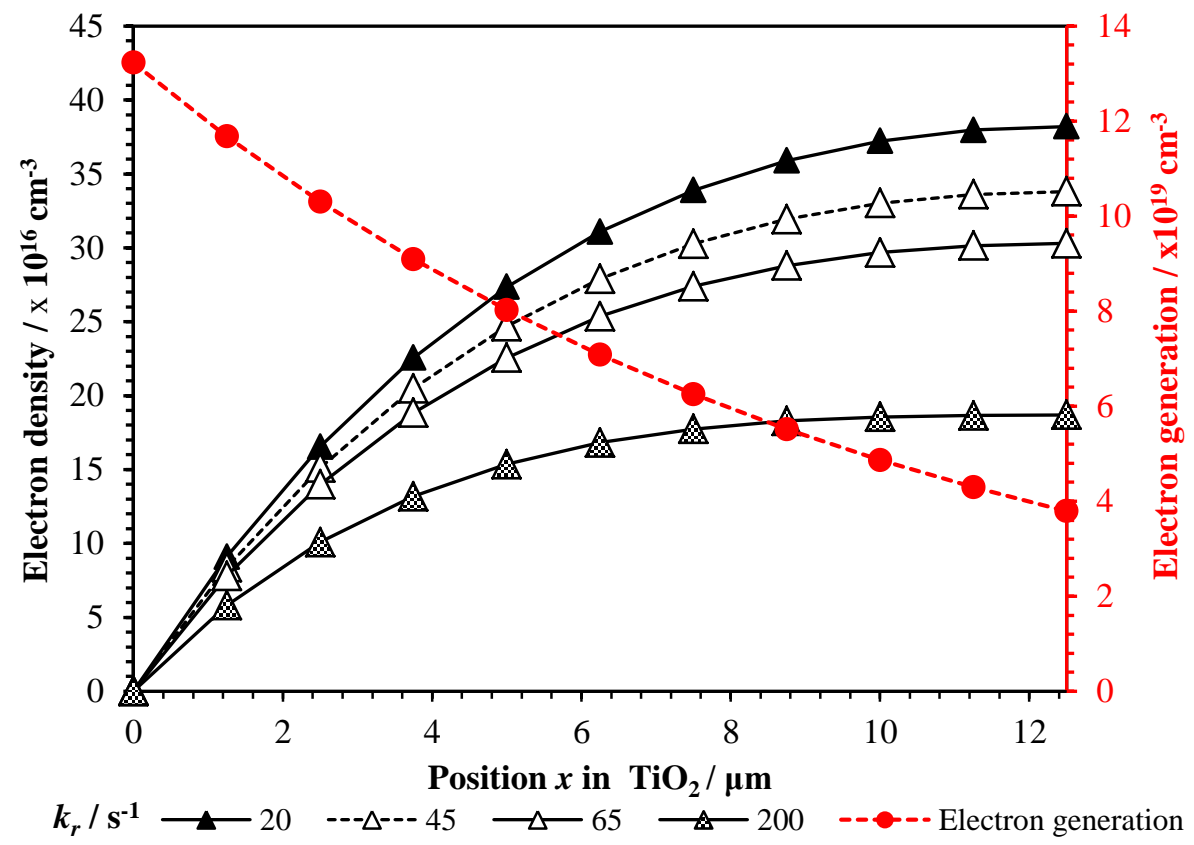

Fig. 6 Simulated electron density profiles for short circuit conditions with different recombination reaction rate constants. All other parameters are presented in Table 1, device B.

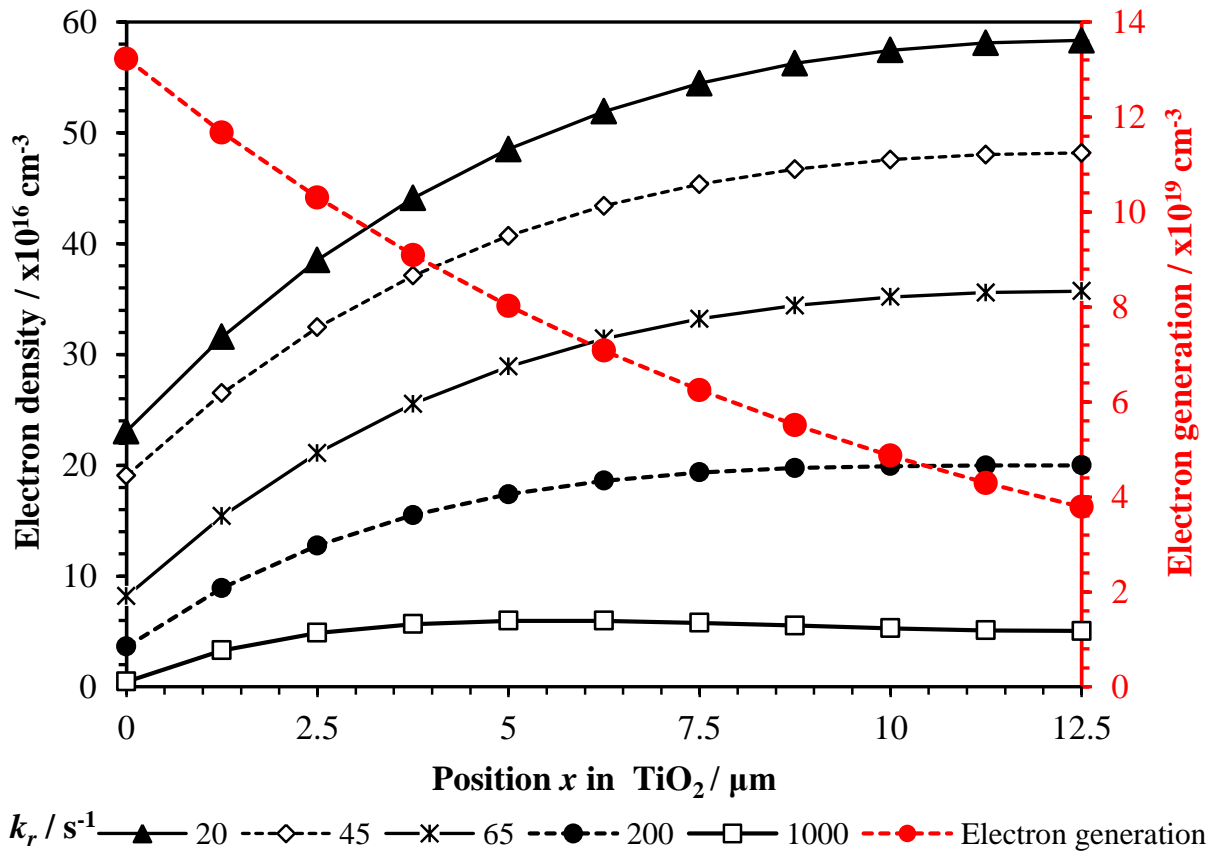

Fig. 7 Simulated electron density profiles for maximum power point with different recombination reaction rate constants. All other parameters are presented in Table 1, device B. 


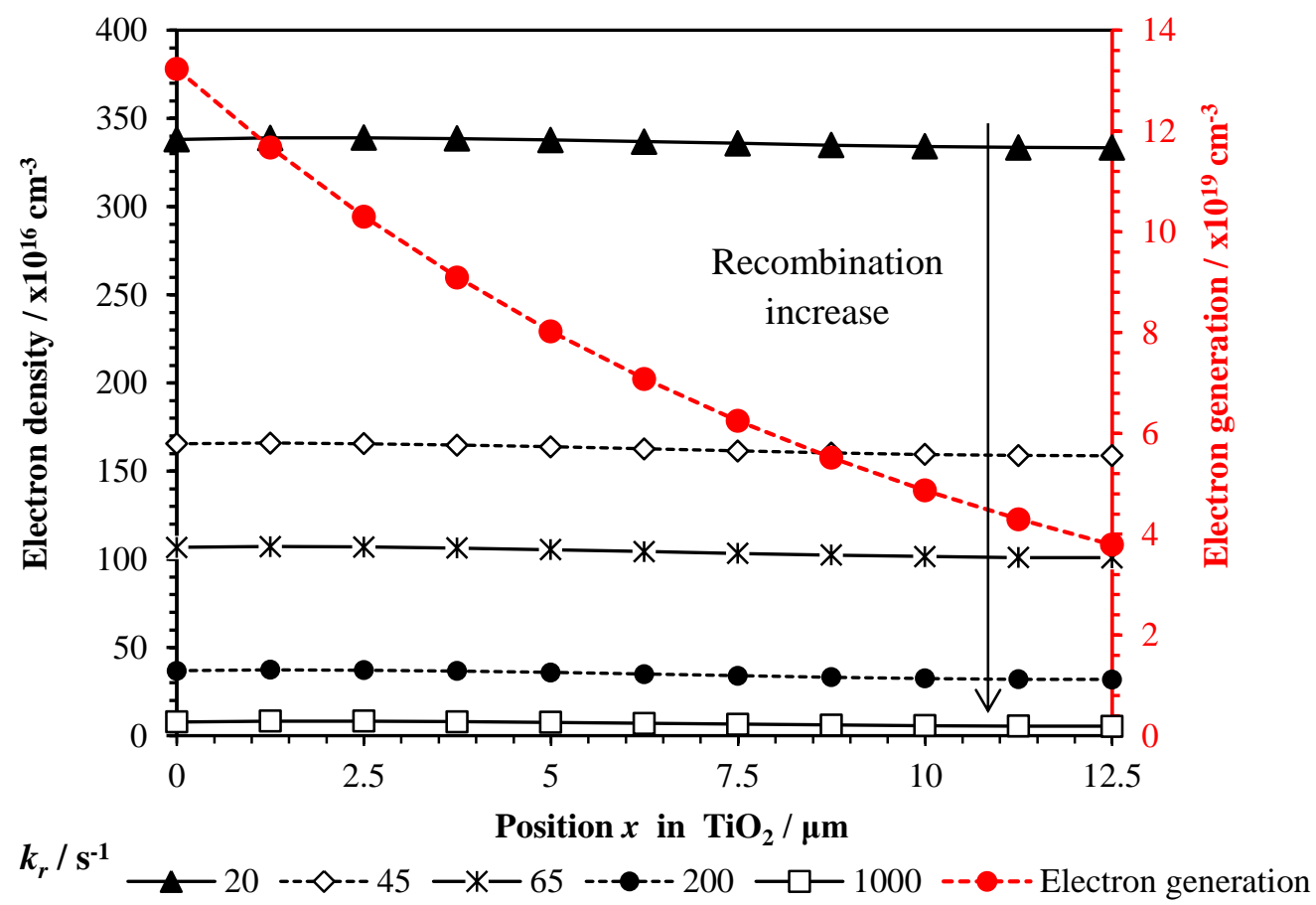

Fig. 8 Simulated electron density profiles for open circuit conditions with different recombination reaction rate constants. All other parameters are presented in Table 1, device B.

At open circuit conditions the recombination flux matches the photocurrent and there are no electrons flowing to the external circuit. At these conditions there is almost no electron gradient, as seen in Figure 8, and this equilibrium determines the open circuit potential, $V_{o c}$, of the device. ${ }^{26}$ Therefore, recombination determines the open potential, $V_{o c}$, of the device and also controls the short circuit current, $J_{s c}$. The excited electron density profiles in the $\mathrm{TiO}_{2}$ film, simulated for different electron recombination rates, enlighten the influence that this reaction has in the open potential, $V_{o c}$, of the solar cell. The electron recombination rate affects the electron flow through the external circuit, and therefore, affects the chemical potential that is built inside the device due to the presence of energy states below the Fermi level of the semiconductor. This way, the amount of electrons that react with the triiodide affects the final potential of the system, as can be confirmed in Figure 8 where higher recombination rates reduce the electron density in the device at open circuit conditions and, by doing so, the chemical potential within the device, acts to reduce the final $V_{o c}$ of the solar cell.

The concentration profiles of the ionic species, shown in Figure 9, are also influenced by recombination. For an illuminated cell, triiodide is formed where there is photon absorption 
and consequently electron injection, due to the regeneration reaction of the oxidized dye with iodide, producing triiodide. Therefore electron generation increases the consumption of iodide and consequently the formation of triiodide. By increasing the recombination reaction rate constant, the amount of electrons that react with triiodide is higher, and thus there is an extra consumption of triiodide besides the amount that is produced by the regeneration reaction of iodide with the oxidized dye. However, because there are less electrons flowing to the external circuit and being returned back to the device through the counter electrode, there is an accumulation of triiodide, mainly at the interface $x=12.5 \mu \mathrm{m}$, where the reduction reaction back to iodide takes place at the platinum catalyst. Along with the extra consumption of triiodide higher $k_{r}$ also causes higher formation of iodide; because the fraction of iodide consumption due to the dye regeneration is independent of $k r$, for higher recombination rates there an accumulation of $\mathrm{I}^{-} \mathrm{s}$ verified for $x=0$ - Figure 9.

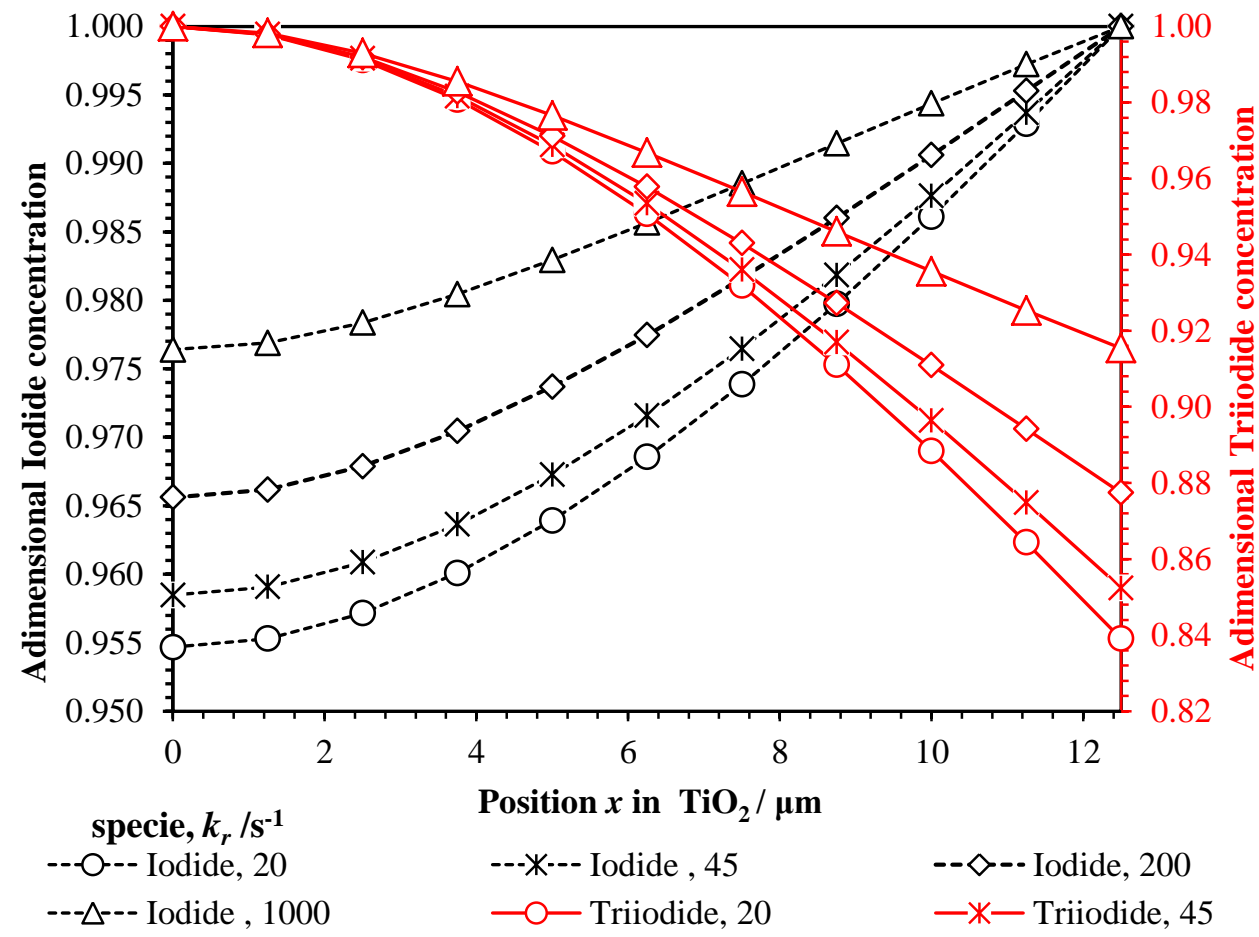

Fig. 9 Simulated ionic concentration profiles for maximum power point for different recombination reaction rate constants. All other parameters are given in Table 1, device B. 
The effect of recombination in the open circuit potential and in the short circuit current is illustrated in Figure 10. In this figure the values of $V_{o c}$ and $J_{s c}$ are plotted as a function of the recombination reaction rate constant for several values of the recombination reaction coefficient $\beta$. The $V_{o c}$ shows a logarithmic dependence as a function of the recombination reaction rate constant across all the values of $k_{r}$ and for all values of $\beta$. The effect of the recombination in the $V_{o c}$ becomes higher for lower values of $\beta$. However, in the case of the $J_{s c}$, apparently there are two distinct logarithmic trends: lower recombination rates $\left(k_{r}<50 \mathrm{~s}^{-1}\right)$ influences less $J_{s c}$ than higher values of $k_{r}$. This fact remains true for $\beta$ values higher than 0.7 . For lower values of $\beta$ (< $0.7)$ the "non-ideality" trend of $J_{s c}$ tends to disappear and the logarithmic dependence remains constant for all values of $k_{r}$. This "non-ideal" trend of $J_{s c}$ vs. $k_{r}$ is verified only for low values of $k_{r}$ and thus for situations where there are almost no recombination in the DSC. Therefore, at these conditions, the $J_{s c}$ does not appear to be recombination-limited; hence the curves tend to predict the same $J_{s c}$ regardless the $\beta$ value, as can be seen in Figure 10. This fact highlights the importance of considering the reaction order especially for high values of $k_{r}$, as it is where there the $\beta$ value influences the most the predicted $J_{s c}$. 

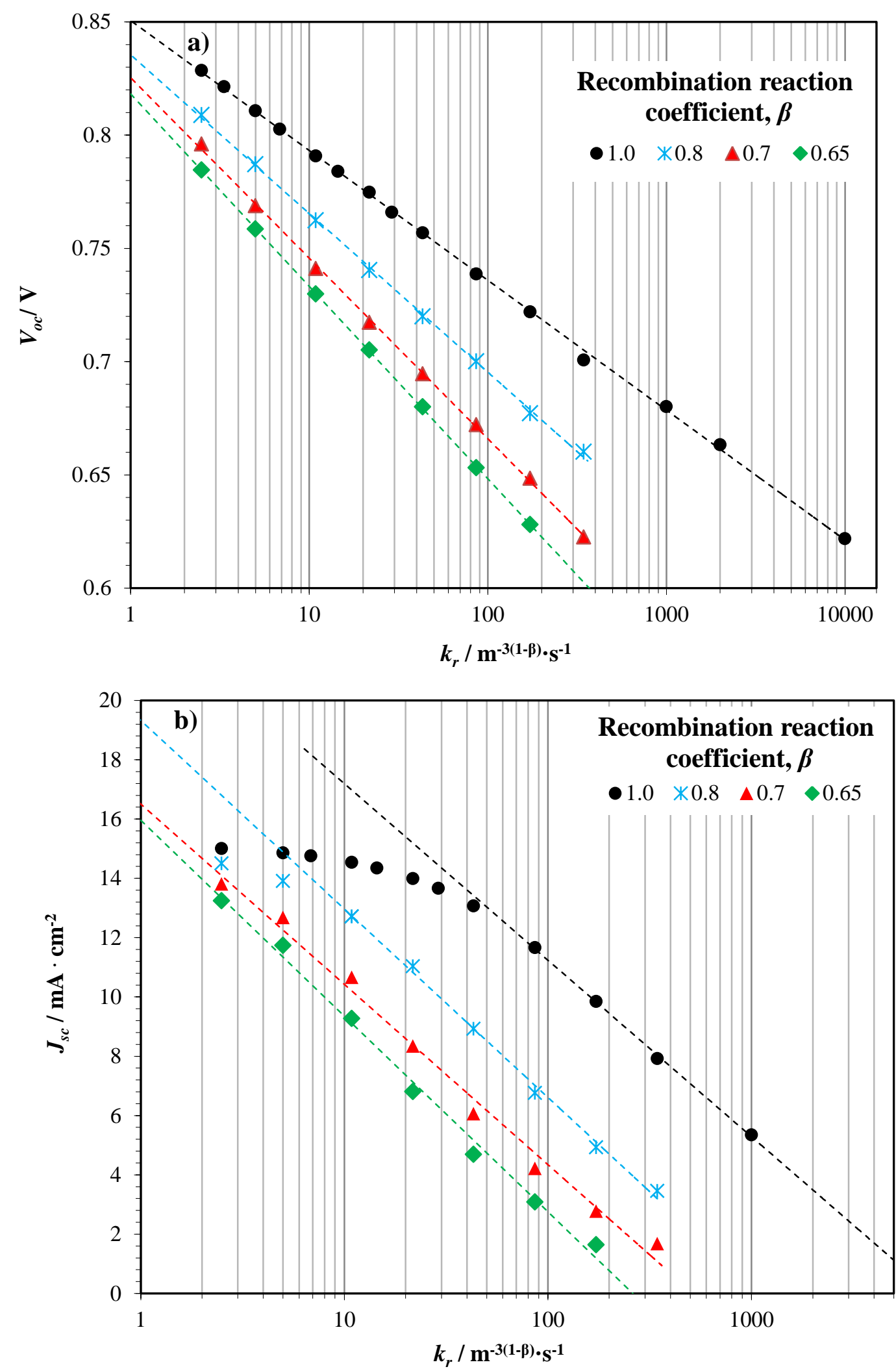

Fig. 10 Influence of the recombination reaction rate constants in the $V_{o c}$ (a) and $J_{s c}$ (b), considering several values of the recombination reaction coefficient, $\beta$. All other parameters are presented in Table 1 , device $\mathrm{B}$. 


\section{Interpretation of recombination in charge extraction experiments}

The previous section studied the influence of the recombination effect on $J_{s c}$ and $V_{o c}$; now, the influence of $k_{r}$ is discussed in terms of charge concentration. Usually charge extraction

experiments are used as a tool to assess limitations in the solar cells. ${ }^{40,43}$ The method relies on the optical perturbation of the solar cell and the correspondent measurement of the output transient electrical signals (current or potential) of the device ${ }^{44,45}$. This approach allows researchers to determine critical information about the electron concentration, transport and recombination inside the solar cell. This is particularly interesting for the development of new materials for DSCs as it allows comparing results from different devices and understanding differences in recombination, collection efficiency, conduction band shifts and other factors that have a crucial role in the final performance of the DSC.

In this section the phenomenological model is used to predict the charge concentration in DSCs for a given set of defined parameters, as a function of $k_{r}$ and $\left(E_{c b}-E_{r e d o x}\right)$. The independent influence that recombination and conduction band shifts have in the plots of charge concentration versus potential in the DSC is evaluated and discussed. Figure 12a shows the charge density as a function of the applied potential calculated for several values of $k_{r}$. The charge concentration shows an exponential increase with the potential applied to the solar cell. Although there is some debate in the academic field, the exponential behavior of charge density versus potential is commonly attributed to the exponential distribution of the trap states below the conduction band edge of $\mathrm{TiO}_{2}$ that are able to accept electrons ${ }^{44}$. Because recombination with electrolyte species is believed to occur with electrons in the conduction band, a vertical shift up of the charge density curves generally means that recombination decreases, see Figure 12a. In this figure, however, the value of $\left(E_{c b}-E_{\text {redox }}\right)$ was kept constant between simulations, which seldom happen experimentally. When comparing recombination rates from experimental charge density results, there is a high probability that a shift in the semiconductor conduction band edge also occurs. The $E_{c b}$ shift is caused by differences in the surface electric field between the $\mathrm{TiO}_{2}$ and the electrolyte. It can be caused by several factors, such as electrolyte 
composition ${ }^{46-49}$, surface treatments of $\mathrm{TiO}_{2}{ }^{50,51}$, dye molecular properties ${ }^{52}$, dye adsorption methods ${ }^{40,53}$, temperature changes ${ }^{54}$, among others. In Figure $12 \mathrm{~b}$ the charge density is plotted versus the applied potential for several values of $\left(E_{c b}-E_{\text {redox }}\right)$ and for $k_{r}=14 \mathrm{~s}^{-1}$. Figure $12 \mathrm{~b}$ shows that a relative shift of $E_{c b}$ compared to $E_{\text {redox }}$ corresponds to a lateral displacement of the curve in the plot. The maximum attainable $V_{o c}$ is affected mainly by two contributions: $\left(E_{c b}-E_{\text {redox }}\right)$ and $k_{r}^{55}$; because $k_{r}$ has been fixed, the difference in the $V_{o c}$ between simulations corresponds to the actual $\Delta\left(E_{c b}-E_{\text {redox }}\right)$ between curves.
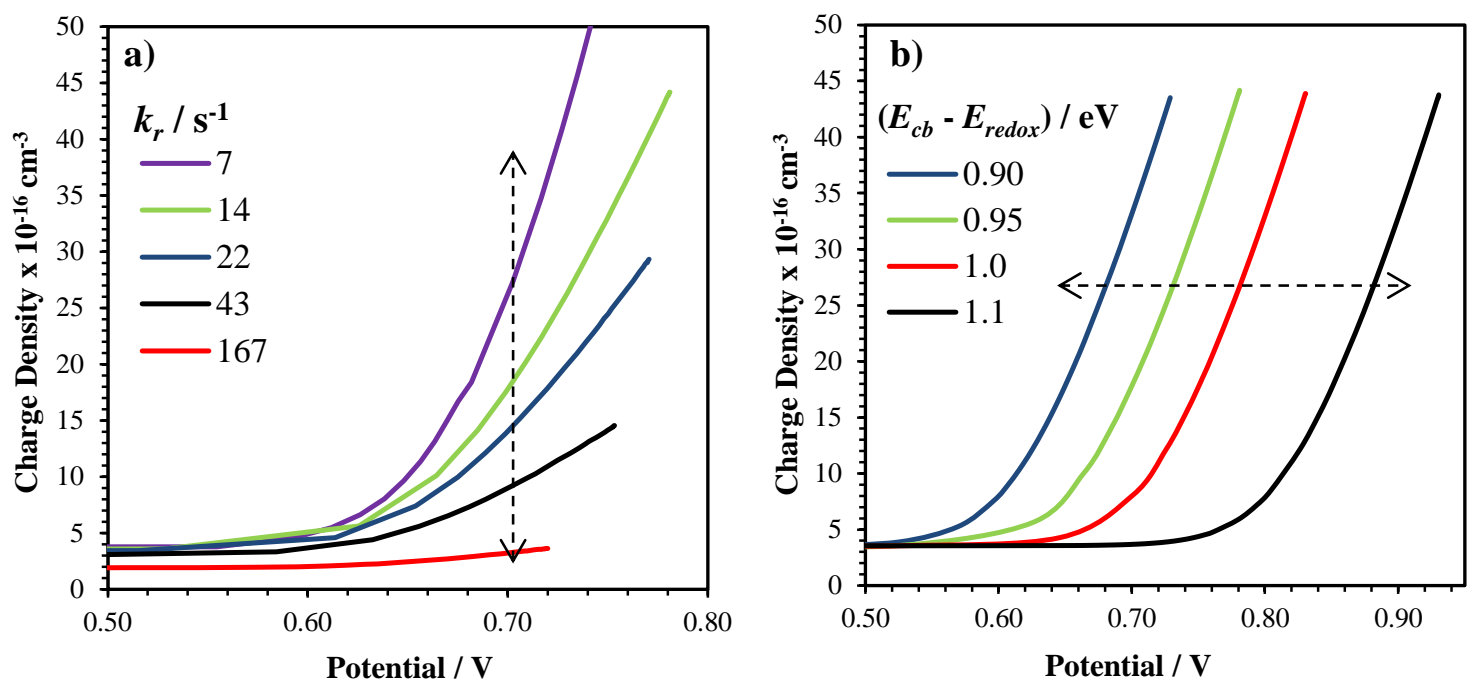

Fig. 11 a) Simulated data of charge density vs. applied potential for several values of $k_{r}$ and ( $E_{c b}$ - $\left.\left.E_{\text {redox }}\right)=0.95 \mathrm{eV}, \mathrm{b}\right)$ Simulated data of charge density vs. applied potential for several values of $\left(E_{c b}\right.$ $E_{\text {redox }}$ ) and $k_{r}=14 \mathrm{~s}^{-1}$. All other parameters are given in Table 1, device B.

When charge extraction experiments are used to compare recombination between cells the $E_{c b}$ shift can mask the effect of changes in $k_{r}{ }^{40,56,57}$. Thus, it is crucial knowing how to decouple both processes for assessing the recombination rates taking into account changes in $E_{c b}$. In Figure 13a changes in $k_{r}$ and shifts in $E_{c b}$ are considered between simulations. This is an example of what could be expected in experimental results. Direct analysis of the plot does not allow taking conclusions about which curve belongs to solar cells with higher or lower recombination rates. In this case, the lateral displacement of the curves caused by the relative change in $E_{c b}$ masks the vertical displacement caused by different recombination rate constants. 

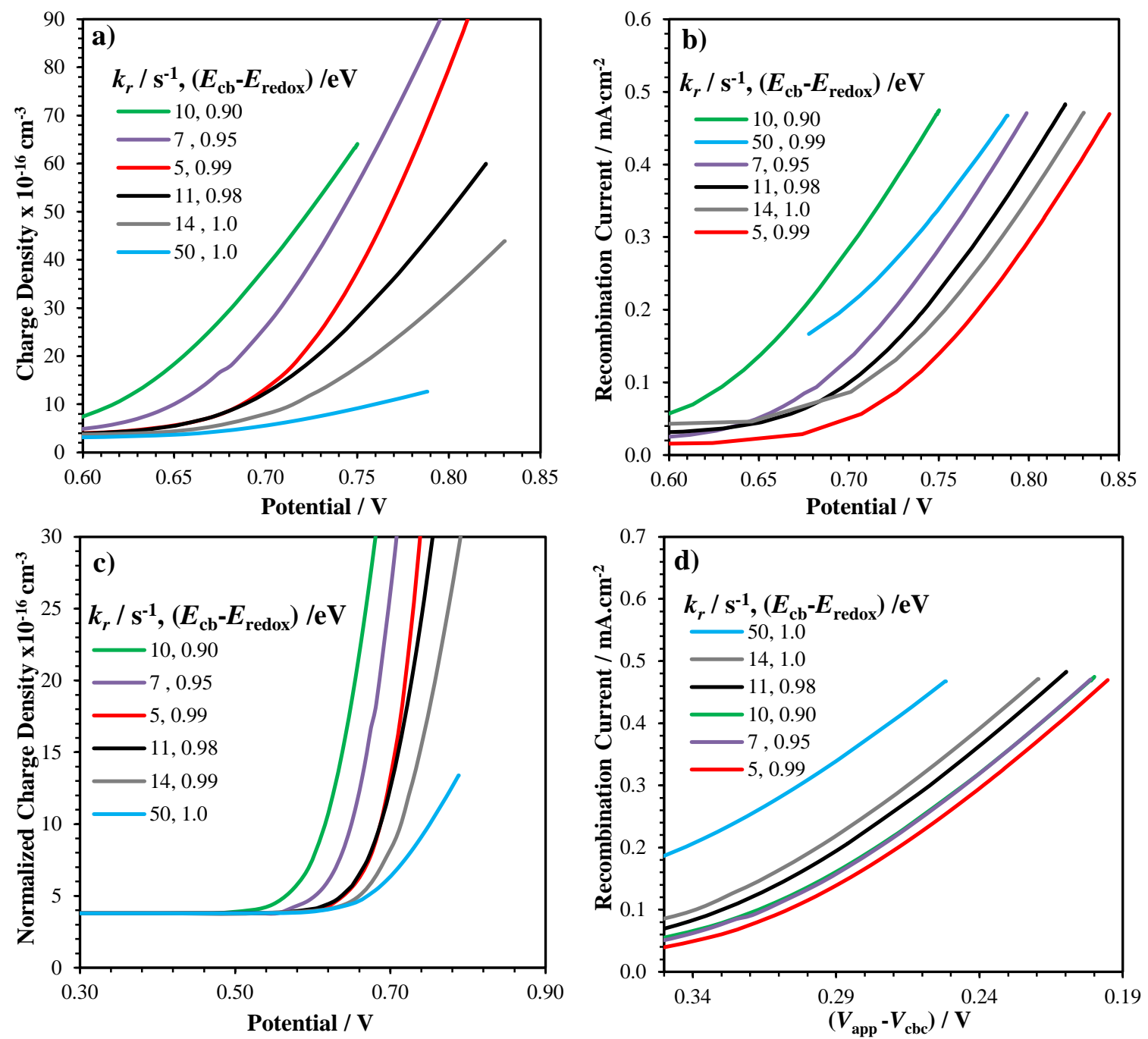

Fig. 12 a) Simulated data of charge density vs. applied potential for several values of $\left(E_{\mathrm{cb}}-E_{\mathrm{redox}}\right)$ (with $k_{r}$ $\left.=14 \mathrm{~s}^{-1}\right)$, b) Simulated data of normalized charge density vs. applied potential for several combinations of $\left(E_{\mathrm{cb}}-E_{\text {redox }}\right)$ and $\left.k_{r}, \mathbf{c}\right)$ Recombination current vs. potential with variable values of $\left(E_{\mathrm{cb}}-E_{\mathrm{redox}}\right)$ and $k_{r}$, without correction of $\left.E_{\mathrm{cb}}, \mathbf{d}\right)$ Recombination current vs. $\left(V_{\mathrm{app}}-V_{\mathrm{cbc}}\right)$ with variable values of values of $\left(E_{\mathrm{cb}}{ }^{-}\right.$ $\left.E_{\text {redox }}\right)$ and $k_{r}$. All other parameters are accordingly with Table 1, device B.

The comparison of recombination rate constants between DSCs can be done, accordingly to some reports, by examining plots of the recombination current vs. potential, calculated by eq. 45 , and shown in Figure $13 \mathrm{~b}^{40}$ :

$$
J_{\text {rec }}=\frac{n_{e^{-}(V)}}{\tau_{e^{-}}}
$$

Because recombination current depends only on the concentration of electrons in the conduction band and on the recombination rate constant, this allows separating the overlap effect of $E_{c b}$ shift. However, plotting $J_{\text {rec }}$ versus potential, Figure $13 \mathrm{~b}$, does not order by recombination 
current the curves of the plot. Even in this case the effect of lateral displacement by $E_{c b}$ shift is verified. Aiming to completely remove this influence and correctly analyze the data, the conduction band shift should be accounted for. To do that, the recombination currents should be compared for the same value of $\left(E_{f}-E_{\text {redox }}\right)$, which means that the comparison should be done for the same amount of free electrons able to recombine with electrolyte. This can be done as follows ${ }^{40}$ :

a. First the shift in the conduction band edge has to be determined. The total charge density, $n_{e^{-}}^{t}$, can be obtained at short circuit conditions for each simulation; then it is subtracted to the $n_{e^{-}}^{t}$ at short circuit of a pre-defined standard simulated curve $\left(k_{r}=7 \mathrm{~s}^{-1}\right.$ and $\left(V_{a p p}-V_{c b c}\right)=$ $0.95 \mathrm{eV}$, purple line in plots from Figure 13). This represents the offset at short-circuit in the total charge density between the two curves. In each simulated curve the offset is added to $n_{e^{-}}^{t}$ for all potentials - Figure 13c. Then the shift in $V_{\mathrm{cb}}\left(\Delta V_{\mathrm{cb}}\right)$ can be estimated directly from the plot by the lateral displacement of each curve - Figure 13c.

b. After $\Delta V_{\mathrm{cb}}$ has been determined it can be added to the $V_{\mathrm{cb}}$ of each curve of Figure $13 \mathrm{~b}$, resulting in curves with a corrected conduction band potential $V_{\mathrm{cbc}}=V_{\mathrm{cb}}+\Delta V_{\mathrm{cb}}$;

c. Then the $V_{\text {cbc }}$ is used to plot $J_{\text {rec }}$ versus $\left(V_{\text {app }}-V_{\text {cbc }}\right)-$ Figure $13 \mathrm{~d}$. In this case, the $V_{\text {cb }}$ was set at $-1 \mathrm{~V}$ vs. electrolyte, which is a common accepted value for iodide/iodine based electrolytes. Afterwards, the curves are placed according to their recombination rate constants, independently of their $\left(E_{\mathrm{cb}}-E_{\mathrm{redox}}\right)$ values, contrary to what is normally found in literature.

\section{Optimization of electrode thickness}

Throughout this work the influence of electron recombination and charge transport in the performance of DSCs was studied. Some critical aspects that must be taken into account in interpreting charge extraction results have been discussed. Now, the relevance of electron recombination and transport within the photoelectrode is evaluated in the design of solar cells. Figure 17 shows the $I-V$ curves for DSCs with several photoelectrode layer thicknesses. 


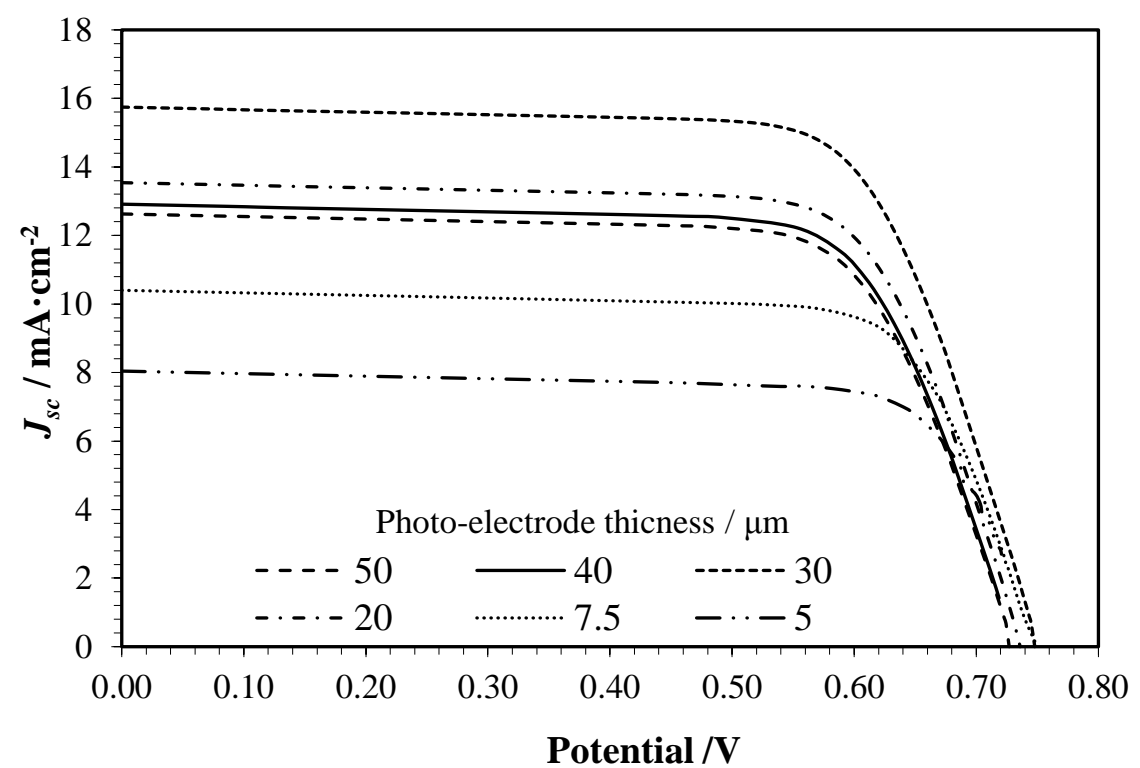

Fig. 13. Influence of the photoelectrode thickness in the DSC $I-V$ characteristics for $k_{r}=50 \mathrm{~s}^{-1}$. All other parameters are given in Table 1, device B.

Figure 17 points out an obvious conclusion: for a given DSC system, there is an optimum thickness of semiconductor. This fact is many times observed in real devices, and is usually optimized experimentally ${ }^{58,59}$. The photo-electrode optimum thickness is related to the length that a generated electron can diffuse before recombining with electrolyte species; this is called diffusion length, $L_{n}{ }^{26,60,61}$. Given a certain effective electron diffusion coefficient, $D_{\text {eff, a }}$ semiconductor thickness, $L_{f}$, and a recombination reaction rate constant, $k_{r}$, two parameters can be defined: the electron lifetime, $\tau_{e^{-}}$, and the transport time, $\tau_{t r}$. The lifetime depends on $k_{r}$, and the transport time on $D_{\text {eff }}$ and $L_{f}$. The charge collection efficiency, $\eta_{c c}$, can now be written; it depends of electron transport in the mesoporous semiconductor and recombination losses. If charge collection is much faster than charge recombination, then $\eta_{c c}$ value will be higher. The electron collection efficiency, $\eta_{c c}$, can be given by ${ }^{62}$ :

$$
\eta_{c c}=\frac{\left[-L_{n} \alpha(\lambda) \cosh \left(\frac{L_{f}}{L_{n}}\right)+\sinh \left(\frac{L_{f}}{L_{n}}\right)+L_{n} \alpha(\lambda) e^{-\alpha(\lambda) L_{f}}\right] L_{n} \alpha}{\left(1-L_{n}{ }^{2} \alpha(\lambda)^{2}\right)\left(1-e^{-\alpha(\lambda) L_{f}}\right) \cosh \left(\frac{L_{f}}{L_{n}}\right)}
$$

The relation between the ratio of lifetime and transport, and the active layer thickness and diffusion length has been established by Bisquert et al. ${ }^{25}$ and included in eq. (46). When $L_{n}$ 
> $L_{f}$, most electrons diffuse through the entire length of photoelectrode before recombining with the electrolyte. On the other hand, in the case of high reactivity, $L_{n} \ll L_{f}$, most electrons recombine at the $\mathrm{TiO}_{2} /$ electrolyte interface.

When recombination does not occur predominantly via the conduction band, the electron diffusion length can no longer be defined as previously, giving rise to a non-linear reaction order ${ }^{29,30}$. Assuming for a defined device that the two ruling processes of transport and recombination are held constant, increasing the semiconductor thickness will reduce the collection efficiency as shown in Figure 18; increasing the recombination, $\eta_{c c}$ still decreases with $L_{f}$. This implies that the optimum thickness of active layer is highly dependent on the relation between transport and recombination in the solar cell.

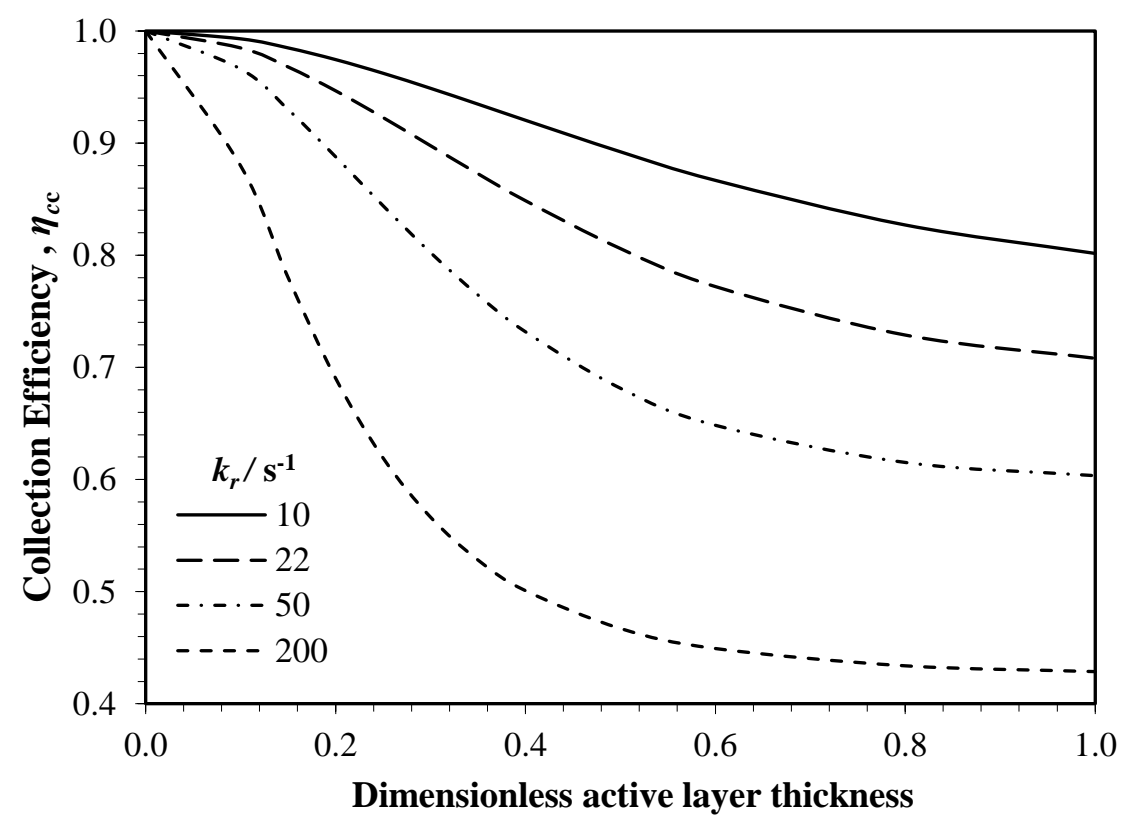

Fig. 14 Collection efficiency determined as a function of the active layer thickness, for several recombination rate constants. All other parameters are given in Table 1, device B.

In the same way, the electron effective diffusion coefficient plays an important role in the collection efficiency. Using a constant value of $k_{r}$, the influence of $D_{\text {eff }}$ in the performance of the DSC can be determined, as illustrated in Figure 19. By increasing $D_{\text {eff }}$ the transport time becomes lower and $\eta_{c c}$ and $\eta$ increase. However, for the assumed device parameters (cf. Table 1, device B) it is necessary to increase $D_{\text {eff }}$ two orders of magnitude to see a clear impact on the 
collection efficiency since the recombination is relatively small. Nonetheless, it is safe to state that the performance of the solar cell would greatly benefit from higher electron conductivities in the semiconductor.

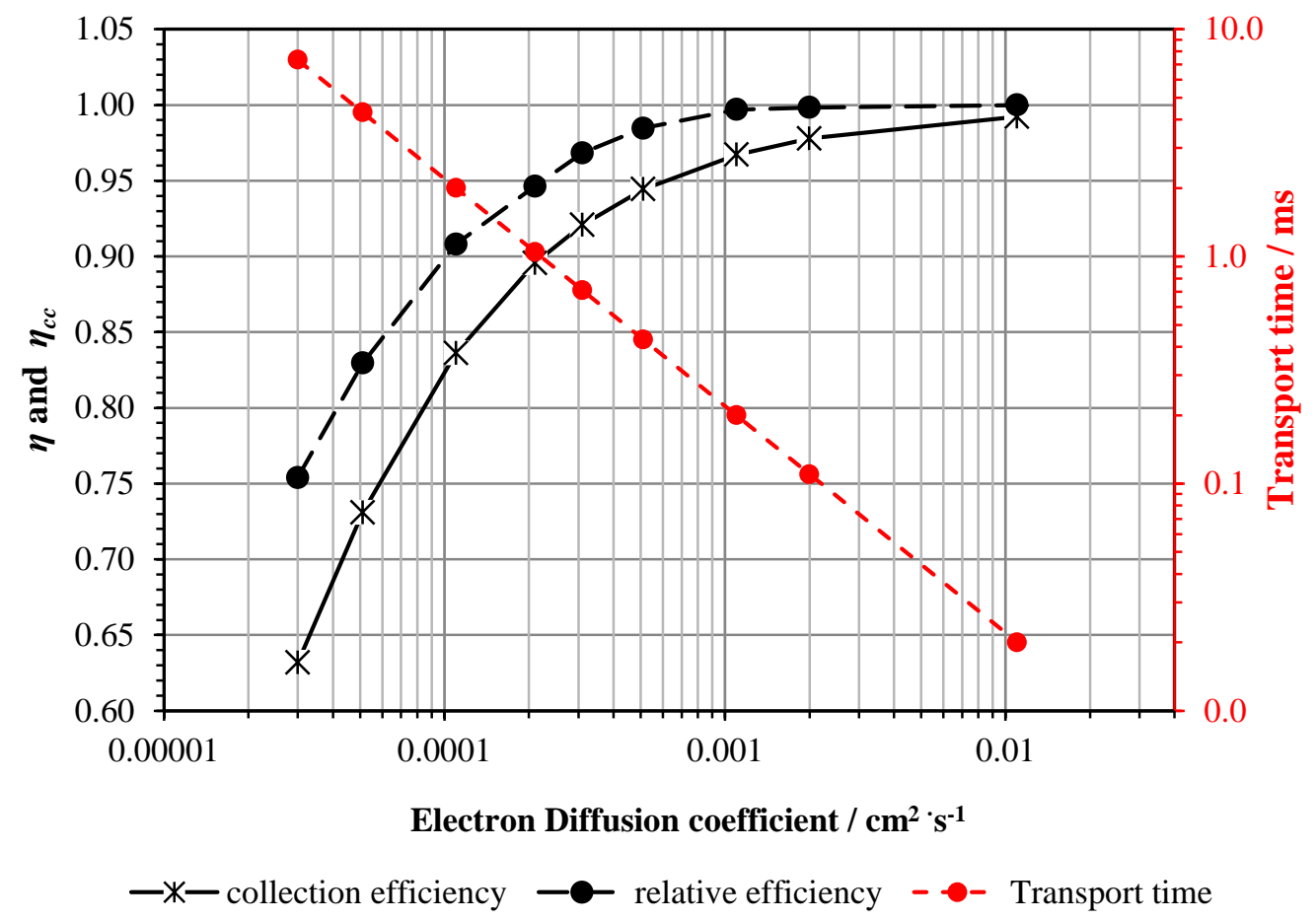

Fig. 15 Collection efficiency, relative efficiency and transport time as a function of the diffusion coefficient. All other parameters are given in Table 1, device B.

Figure 16 shows the curves of efficiency as a function of active layer thickness assuming several $k_{r}$ and $D_{\text {eff }}$ values. The two plots highlight quantitatively the influence that recombination and transport have in the performance of DSCs. For example, assuming $k_{r}=10 \mathrm{~s}^{-}$ 1 (low recombination rate; reference recombination rate is $k_{r}=200 \mathrm{~s}^{-1}$ ), the optimum photoelectrode thickness is twice the normal thickness (from $15 \mu \mathrm{m}$ to $30 \mu \mathrm{m}$ ) and the DSC efficiency increases more than 2 percentage points (from $8 \%$ to $10 \%$ ). The highlighted points in the curves in Figure 16 (black diamonds) are the respective optimum thicknesses values. As expected, as the recombination rate decreases and/or the electron diffusivity increases, the optimum photoelectrode thickness increases. Figure 17 shows that the influence of $k_{r}$ and $D_{\text {eff }}$ at the optimum photoelectrode thickness is exponential. 

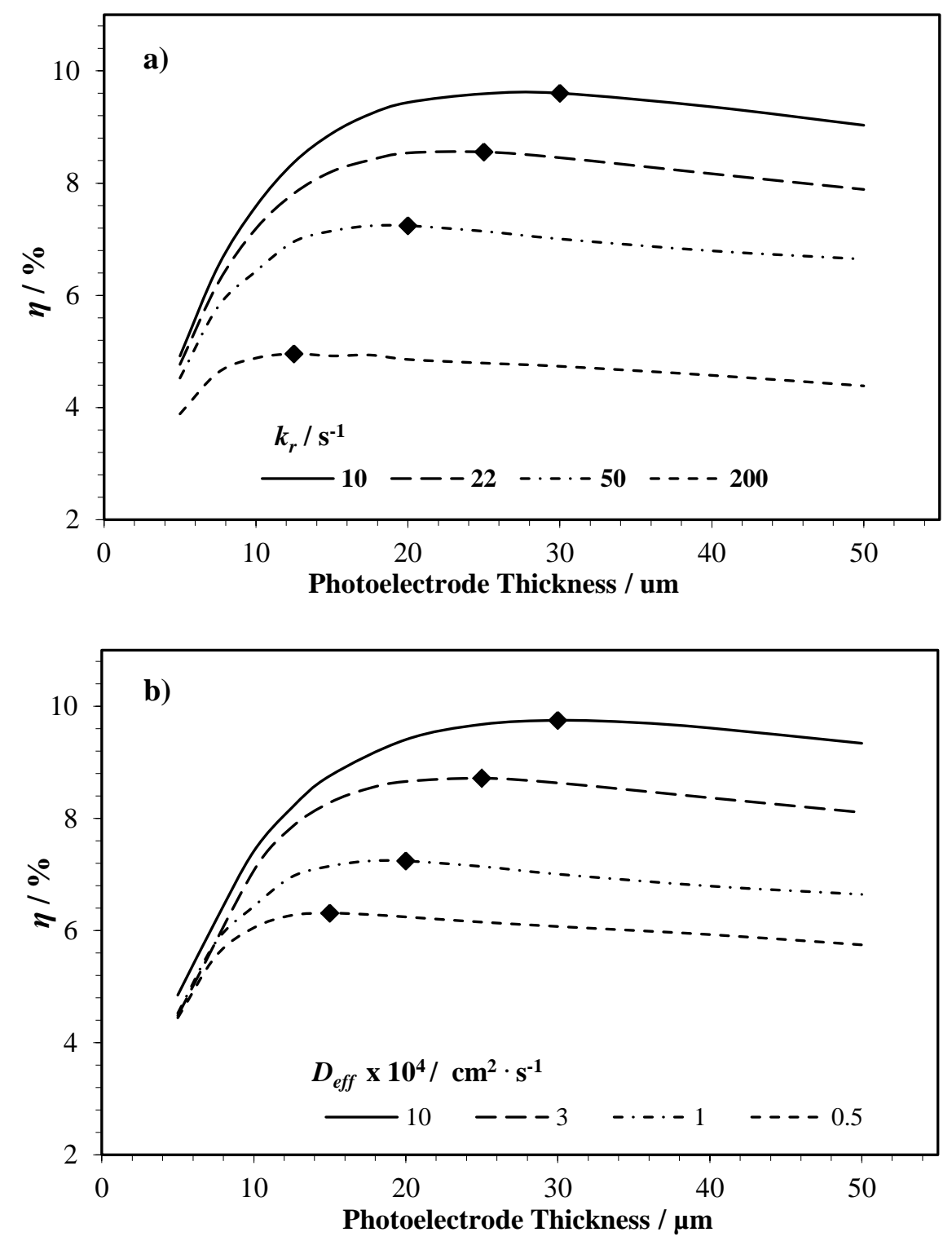

Fig. 16 a) Efficiency vs. photoelectrode thickness, for several $k_{r}$ and $\left.D_{\text {eff }}=1.10 \times 10^{-4} \mathrm{~cm}^{-2} \cdot \mathrm{s}^{-1} ; \mathbf{b}\right)$ Efficiency vs. photoelectrode thickness, for several values of $D_{\text {eff }}$ and $k_{r}=20 \mathrm{~s}^{-1}$. The black diamonds are the maximum efficiency values for each curve. All other parameters are given in Table 1, device B. 


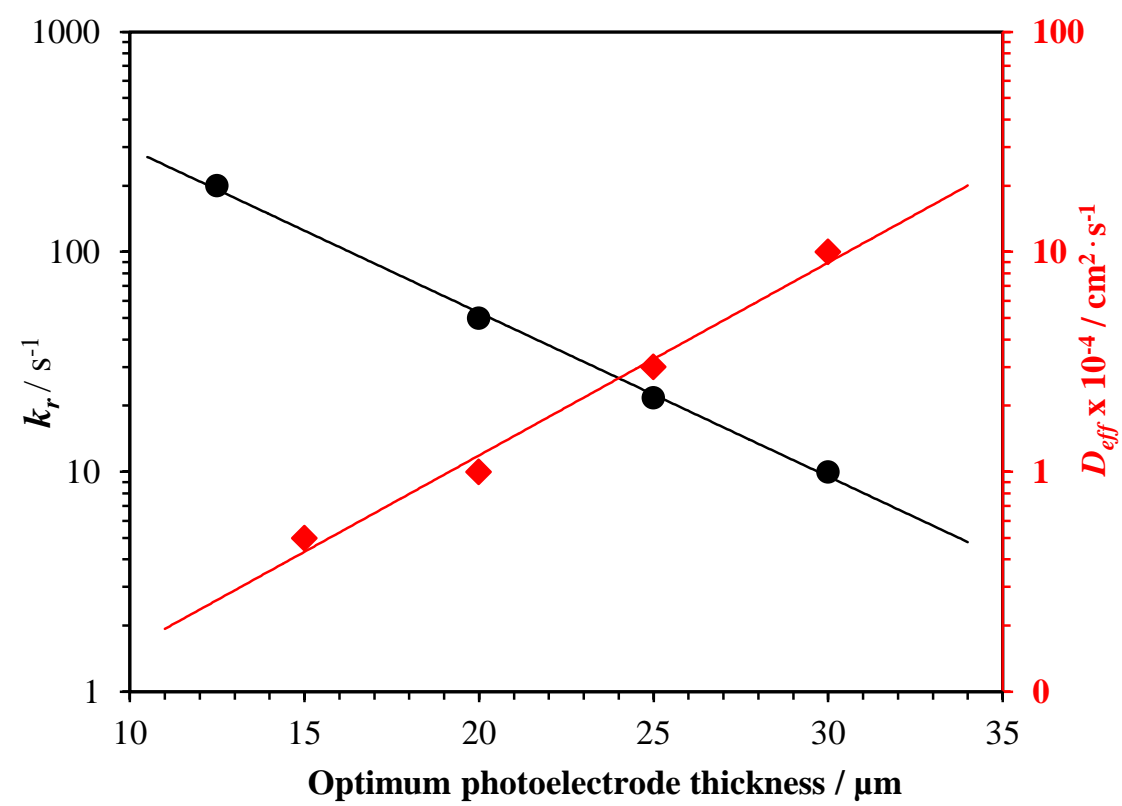

Fig. 17 Influence of $k_{r}$ and $D_{\text {eff }}$ for the optimum photoelectrode thickness. The parameters used for the simulations are given in Table 1.

In fact, a very recent report by Crossland et al. ${ }^{63}$ showed that a new mesoporous $\mathrm{TiO}_{2}$ single crystal has electronic mobility values over one order of magnitude higher than the typical $\mathrm{TiO}_{2}$ mesoporous film. This development resulted in an efficiency boost of almost $130 \%$ in a solid state device. The reported electronic mobility should allow increasing the optimal thickness of the photoelectrodes in current DSC cells. Using the optimization curves of Figure 21 and $10^{-2} \mathrm{~cm}^{2} \cdot \mathrm{s}^{-1}$ as the new electron diffusion coefficient (typical values coefficients in anatase $\mathrm{TiO}_{2}$ ranges between $10^{-4}$ to $10^{-5} \mathrm{~cm}^{2} \cdot \mathrm{s}^{-1} 10,63$ ), the optimum thickness for the new material should be around $40 \mu \mathrm{m}$ and the energy efficiency could increase to $12 \%$. If one considers the use of the new porphyrin dye with cobalt (II/III)-based redox electrolyte for attaining open circuit voltages near $1 \mathrm{~V}^{2}$, a $15 \%$ DSC could be expected in a near future.

\section{Conclusions}

Phenomenological modeling is a powerful tool to study the fundamentals of DSC operation. The transient model used considers the continuity equations for the three modeled species (electrons, iodide and triiodide) and their respective initial and boundary conditions. It is 
assumed that the cell is irradiated perpendicularly to the photoelectrode and that each absorbed photon generates one injected electron into the $\mathrm{TiO}_{2}$ conduction band. Only one possible mechanism for electron loss is assumed, corresponding to the recombination reaction of electrons with electrolyte species. The presented phenomenological model is able to properly simulate steady state $I$ - $V$ curves of dye-sensitized solar cells. The model has been used as a simulation tool to assess the two processes that rule the performance of DSCs: electron transport and recombination. The quantitatively effect of the recombination reaction rate constant, $k_{r}$, and the electron diffusion coefficient, $D_{\text {eff }}$, in the collection efficiency was shown and discussed. The influence of $k_{r}$ in the $V_{o c}$ and $J_{s c}$ of DSCs has been determined and has been shown to be highly dependent on the recombination reaction kinetics.

The model was used to evaluate the influence that conduction band shifts have in charge extraction experiments. The described methodology is able to decouple the conduction band shifts from the recombination effect. This is particularly useful for material synthesis where charge experiments are used to assess changes in the recombination rate constants between different samples.

It simulated the influence that electron transport and recombination have in the optimization of the photoelectrode thickness. It was found that the optimum photoelectrode thickness varies exponentially with the recombination rate and with the electron diffusion coefficient. The optimization procedure developed is particularly interesting when developing high efficiency DSCs.

\section{Acknowledgements}

J. Maçaira is grateful to the Portuguese Foundation for Science and Technology (FCT) for his PhD Grant (Reference: SFRH/BD/80449/2011). L. Andrade acknowledges European Research Council for funding within project BI-DSC - Building Integrated Dye sensitized Solar Cells (Contract Number: 321315). Financial support by FCT through the project SolarConcept (Reference PTDC/EQU-EQU/120064/2010) and WinDSC SI\&IDT (Reference 21539/2011) is also acknowledged. 


\section{Nomenclature}

\begin{tabular}{|c|c|c|c|}
\hline$A$ & Cell area, $\mathrm{m}^{2}$ & $V_{\mathrm{cb}}$ & Conduction band potential, $\mathrm{V}$ \\
\hline$C_{i}$ & Concentration of species $i, \mathrm{M}$ & $V_{\mathrm{cbc}}$ & Corrected conduction band potential, $\mathrm{V}$ \\
\hline$D a$ & $\begin{array}{l}\text { Dimensionless number (equivalent to } \\
\text { Damkolher number) }\end{array}$ & $V_{\text {ext }}$ & External cell potential, $\mathrm{V}$ \\
\hline$D_{i}$ & Diffusion coefficient of species $i, \mathrm{~m}^{2} \cdot \mathrm{s}^{-1}$ & $V_{\text {int }}$ & Internal cell potential, $\mathrm{V}$ \\
\hline$D_{\text {ref }}$ & Reference diffusion coefficient, $\mathrm{m}^{2} \cdot \mathrm{s}^{-1}$ & $V_{o c}$ & Open-circuit potential, $\mathrm{V}$ \\
\hline$E$ & Energy, J & $V_{f}$ & Fermi level potential, V \\
\hline$E_{c b}$ & Conduction band energy, $\mathrm{J}$ & $X$ & Coordinate, $\mathrm{m}$ \\
\hline$E_{c b c}$ & Corrected conduction band energy, J & & Greek letters \\
\hline$E_{f}$ & Fermi Energy, J & $\alpha(\lambda)$ & $\begin{array}{l}\text { Wavelength-dependent absorption } \\
\text { coefficient } \mathrm{m}^{-1}\end{array}$ \\
\hline$E_{f}^{e q}$ & Dark equilibrium Fermi energy, J & $B$ & Recombination reaction order \\
\hline$E_{\text {redox }}$ & Redox energy, J & $A$ & Symmetry coefficient \\
\hline$E_{\text {redox }}^{0}$ & Standard redox energy, J & $\Gamma$ & Dimensional number \\
\hline$E_{\text {redox }}^{o c}$ & Open circuit redox energy, $\mathrm{J}$ & $\Delta V_{\mathrm{int}}$ & Variation of the applied potential, $\mathrm{V}$ \\
\hline$F F$ & Fill factor & $\Delta V_{\mathrm{cb}}$ & $\begin{array}{l}\text { Shift in the conduction band potential, } \\
\text { V }\end{array}$ \\
\hline$G_{i}$ & Generation rate of specie $\mathrm{i}, \mathrm{m}^{-3} \mathrm{~s}^{-1}$ & $E$ & Porosity of the $\mathrm{TiO}_{2}$ film \\
\hline$h$ & Planck constant & $\eta_{P t}$ & $\begin{array}{l}\text { Electrochemical overpotential at Pt } \\
\text { electrode, } \mathrm{V}\end{array}$ \\
\hline$I$ & Electric current, A & $\eta_{\text {inj }}$ & Electron injection efficiency \\
\hline$I_{s}$ & Incident photon flux, $\mathrm{m}^{2} \cdot \mathrm{s}^{-1}$ & $\theta$ & Dimensionless time variable \\
\hline$j_{i}$ & Current density of species $\mathrm{i}, \mathrm{A} \cdot \mathrm{m}^{-2}$ & $\lambda$ & Wavelength, m \\
\hline$j_{s c}$ & Short circuit current density, $\mathrm{A} \cdot \mathrm{m}^{-2}$ & $\tau_{\mathrm{e}-}$ & Electron lifetime, $\mathrm{s}$ \\
\hline$j_{0}$ & $\begin{array}{l}\text { Exchange current density at the counter } \\
\text { electrode, } \mathrm{A} \cdot \mathrm{m}^{-2}\end{array}$ & $\phi$ & $\begin{array}{l}\text { Dimensionless number (Equivalent to } \\
\text { Thiele modulus) }\end{array}$ \\
\hline$j_{r e c}$ & Recombination current, $\mathrm{A} \cdot \mathrm{m}^{-2}$ & init & Initial conditions \\
\hline$k_{B}$ & Boltzmann constant, $\mathrm{J} \cdot \mathrm{K}^{-1}$ & $t$ & total \\
\hline$k_{r}$ & Recombination reaction constant, $\mathrm{m}^{-3(1-\beta)} \cdot \mathrm{s}^{-1}$ & $0^{+}$ & $\mathrm{xx}$ coordinate close to the photoanode \\
\hline$L_{f}$ & Thickness of the $\mathrm{TiO}_{2}$ film & $0^{-}$ & External point of the current collector \\
\hline$n_{i}$ & Density of specie $i, \mathrm{~m}^{-3}$ & \multicolumn{2}{|c|}{ Superscript } \\
\hline$n_{e q}$ & Dark equilibrium electron density, $\mathrm{m}^{-3}$ & * & $\begin{array}{l}\text { Dimensionless variable } \\
\text { total }\end{array}$ \\
\hline$n_{\text {ref }}$ & Reference particle density, $\mathrm{m}^{-3}$ & \multicolumn{2}{|c|}{ Subscripts } \\
\hline$N_{C B}$ & $\begin{array}{l}\text { Effective density of states in the } \mathrm{TiO}_{2} \\
\text { conduction band, } \mathrm{m}^{-3}\end{array}$ & $c^{+}$ & Cations \\
\hline$q$ & Elementary charge, $\mathrm{C}$ & $\mathrm{CB}$ & Conduction band \\
\hline$R_{i}$ & Recombination rate of species $\mathrm{I} \mathrm{m}^{-3} \cdot \mathrm{s}^{-1}$ & $\mathrm{CE}$ & Counter electrode \\
\hline$R_{p}$ & Shunt resistances, $\Omega$ & $\mathrm{e}^{-}$ & Electrons \\
\hline$R_{\text {series }}$ & External series resistances, $\Omega$ & $\mathrm{I}^{-}$ & Iodide \\
\hline$R_{c}$ & Contact and wire series resistances, $\Omega$ & $\mathrm{I}_{3}^{-}$ & Triiodide \\
\hline$R_{T C O}$ & $\begin{array}{l}\text { Transparent conductive oxide sheet } \\
\text { resistance, } \Omega\end{array}$ & MPP & Maximum Power point \\
\hline$R_{\text {ext }}$ & Load parameter: external resistance, $\Omega$ & $\mathrm{OC}$ & Open circuit \\
\hline$T$ & Temperature, $\mathrm{K}$ & $\mathrm{SC}$ & Short-circuit \\
\hline$t$ & Time, s & $\mathrm{TCO}$ & Transparent conductive oxide \\
\hline
\end{tabular}




\section{References}

1. J. H. Heo, S. H. Im, J. H. Noh, T. N. Mandal, C.-S. Lim, J. A. Chang, Y. H. Lee, H.-j. Kim, A. Sarkar, K. NazeeruddinMd, M. Gratzel and S. I. Seok, Nat Photon, 2013, 7, 486-491.

2. A. Yella, H.-W. Lee, H. N. Tsao, C. Yi, A. K. Chandiran, M. K. Nazeeruddin, E. W.-G. Diau, C.-Y. Yeh, S. M. Zakeeruddin and M. Grätzel, Science, 2011, 334, 629-634.

3. J. Burschka, N. Pellet, S.-J. Moon, R. Humphry-Baker, P. Gao, M. K. Nazeeruddin and M. Gratzel, Nature, 2013.

4. B. O'Regan and M. Grätzel, Nature, 1991, 353, 737-740.

5. M. Grätzel, Inorg. Chem., 2005, 44, 6841-6851.

6. M. Grätzel and J. R. Durrant, in Nanostructured and photoelectrochemical systems for solar photon conversion, Imperial College Press, London, 2008, ch. 8.

7. M. D. Archer and A. J. Nozik, Nanostructured and photoelectrochemical systems for solar photon conversion, Imperial College Press ; World Scientific Pub. Co., London; Singapore; Hackensack, NJ, 2008.

8. L. R. Andrade, H. A.; Mendes, A, Dye-Sensitized Solar Cells: an Overview, in Energy Production and Storage: Inorganic Chemical Strategies for a Warming World, John Wiley \& Sons, Ltd, Chichester, UK, 2010.

9. M. Wang, P. Chen, R. Humphry-Baker, S. M. Zakeeruddin and M. Gratzel, ChemPhysChem, 2009, 10, 290-299.

10. G. He, L. Zhao, Z. Zheng and F. Lu, Journal of Physical Chemistry C, 2008, 112, 18730-18733.

11. J. Shi, B. Peng, J. Pei, S. Peng and J. Chen, Journal of Power Sources, 2009, 193, 878884.

12. G. Boschloo, L. Haggman and A. Hagfeldt, J. Phys. Chem. B, 2006, 110, 13144-13150.

13. S. Y. Huang, G. Schlichthorl, A. J. Nozik, M. Gratzel and A. J. Frank, The Journal of Physical Chemistry B, 1997, 101, 2576-2582.

14. S. Nakade, Y. Makimoto, W. Kubo, T. Kitamura, Y. Wada and S. Yanagida, J. Phys. Chem. B, 2005, 109, 3488-3493.

15. S. Nakade, T. Kanzaki, W. Kubo, T. Kitamura, Y. Wada and S. Yanagida, J. Phys. Chem. B, 2005, 109, 3480-3487.

16. F. Matar, T. H. Ghaddar, K. Walley, T. DosSantos, J. R. Durrant and B. O'Regan, Journal of Materials Chemistry, 2008, 18, 4246-4253.

17. P. M. Sommeling, B. C. O'Regan, R. R. Haswell, H. J. P. Smit, N. J. Bakker, J. J. T. Smits, J. M. Kroon and J. A. M. vanRoosmalen, J. Phys. Chem. B, 2006, 110, 1919119197. 
18. N. Tetreault and M. Gratzel, Energy \& Environmental Science, 2012.

19. N. Tétreault, É. Arsenault, L.-P. Heiniger, N. Soheilnia, J. Brillet, T. Moehl, S. Zakeeruddin, G. A. Ozin and M. Grätzel, Nano Letters, 2011, 11, 4579-4584.

20. B. Mandlmeier, J. M. Szeifert, D. Fattakhova-Rohlfing, H. Amenitsch and T. Bein, Journal of the American Chemical Society, 2011, 133, 17274-17282.

21. S. Guldin, S. Hüttner, M. Kolle, M. E. Welland, P. Müller-Buschbaum, R. H. Friend, U. Steiner and N. Tétreault, Nano Letters, 2010, 10, 2303-2309.

22. J. N. Clifford, M. Planells and E. Palomares, Journal of Materials Chemistry, 2012, 22, 24195-24201.

23. J. Maçaira, L. Andrade and A. Mendes, Renewable and Sustainable Energy Reviews, 2013, 27, 334-349.

24. L. Andrade, J. Sousa, H. A. Ribeiro and A. Mendes, Solar Energy, 2011, 85, 781-793.

25. J. Bisquert, The Journal of Physical Chemistry B, 2002, 106, 325-333.

26. J. Bisquert and I. n. Mora-Seró, The Journal of Physical Chemistry Letters, 2009, 1, 450-456.

27. Y. Liu, A. Hagfeldt, X.-R. Xiao and S.-E. Lindquist, Solar Energy Materials and Solar Cells, 1998, 55, 267-281.

28. P. R. F. Barnes, L. Liu, X. Li, A. Y. Anderson, H. Kisserwan, T. H. Ghaddar, J. R. Durrant and B. C. O’Regan, Nano Letters, 2009, 9, 3532-3538.

29. J. Villanueva-Cab, H. Wang, G. Oskam and L. M. Peter, The Journal of Physical Chemistry Letters, 2010, 1, 748-751.

30. J. P. Gonzalez-Vazquez, G. Oskam and J. A. Anta, The Journal of Physical Chemistry C, 2012, 116, 22687-22697.

31. J. A. Anta, J. Idigoras, E. Guillen, J. Villanueva-Cab, H. J. Mandujano-Ramirez, G. Oskam, L. Pelleja and E. Palomares, Physical Chemistry Chemical Physics, 2012, 14, 10285-10299.

32. J. Ferber, R. Stangl and J. Luther, Solar Energy Materials and Solar Cells, 1998, 53, 29-54.

33. K. Nithyanandam and R. Pitchumani, Solar Energy, 2012, 86, 351-368.

34. M. Penny, T. Farrell and G. Will, Solar Energy Materials and Solar Cells, 2008, 92, 2437.

35. A. Ofir, L. Grinis and A. Zaban, The Journal of Physical Chemistry C, 2008, 112, 27792783.

36. A. Hagfeldt, G. Boschloo, L. Sun, L. Kloo and H. Pettersson, Chemical Reviews, 2010, 110, 6595-6663.

37. L. Petzold, Siam J. Sci. Stat. Computing, 1983, 4, 136-148. 
38. F. Ribeiro, Maçaira,J. , Cruz, R., Gabriel, J., Andrade, L., Mendes, A., Solar Energy Materials and Solar Cells, 2012, 96, 43-49.

39. H. J. Snaith, Advanced Functional Materials, 2010, 20, 13-19.

40. B. O'Regan, L. Xiaoe and T. Ghaddar, Energy \& Environmental Science, 2012, 5, $7203-$ 7215 .

41. S. Zhang, X. Yang, Y. Numata and L. Han, Energy \& Environmental Science, 2013, 6, 1443-1464.

42. B. C. O'Regan and J. R. Durrant, The Journal of Physical Chemistry B, 2006, 110, 8544-8547.

43. P. Docampo, S. Guldin, U. Steiner and H. J. Snaith, The Journal of Physical Chemistry Letters, 2013, 4, 698-703.

44. P. R. F. Barnes, K. Miettunen, X. Li, A. Y. Anderson, T. Bessho, M. Gratzel and B. C. O'Regan, Advanced Materials, 2013, 25, 1881-1922.

45. L. M. Peter, The Journal of Physical Chemistry C, 2007, 111, 6601-6612.

46. S. A. Haque, E. Palomares, B. M. Cho, A. N. M. Green, N. Hirata, D. R. Klug and J. R. Durrant, J. Am. Chem. Soc., 2005, 127, 3456-3462.

47. F. Fabregat-Santiago, J. Bisquert, G. Garcia-Belmonte, G. Boschloo and A. Hagfeldt, Solar Energy Materials and Solar Cells, 2005, 87, 117-131.

48. H. Wang and L. M. Peter, The Journal of Physical Chemistry C, 2012, 116, 1046810475 .

49. B. C. O'Regan, K. Bakker, J. Kroeze, H. Smit, P. Sommeling and J. R. Durrant, The Journal of Physical Chemistry B, 2006, 110, 17155-17160.

50. B. C. O'Regan, J. R. Durrant, P. M. Sommeling and N. J. Bakker, The Journal of Physical Chemistry C, 2007, 111, 14001-14010.

51. X. Wu, L. Wang, F. Luo, B. Ma, C. Zhan and Y. Qiu, The Journal of Physical Chemistry C, 2007, 111, 8075-8079.

52. E. Ronca, M. Pastore, L. Belpassi, F. Tarantelli and F. De Angelis, Energy \& Environmental Science, 2013, 6, 183-193.

53. A. B. F. Martinson, M. r. S. Góes, F. Fabregat-Santiago, J. Bisquert, M. J. Pellin and J. T. Hupp, The Journal of Physical Chemistry A, 2009, 113, 4015-4021.

54. S. R. Raga and F. Fabregat-Santiago, Physical Chemistry Chemical Physics, 2013, 15, 2328-2336.

55. S. R. Raga, E. M. Barea and F. Fabregat-Santiago, The Journal of Physical Chemistry Letters, 2012, 3, 1629-1634. 
56. H.-P. Wu, Z.-W. Ou, T.-Y. Pan, C.-M. Lan, W.-K. Huang, H.-W. Lee, N. M. Reddy, C.-T. Chen, W.-S. Chao, C.-Y. Yeh and E. W.-G. Diau, Energy \& Environmental Science, 2012, 5, 9843-9848.

57. H.-P. Wu, C.-M. Lan, J.-Y. Hu, W.-K. Huang, J.-W. Shiu, Z.-J. Lan, C.-M. Tsai, C.-H. Su and E. W.-G. Diau, The Journal of Physical Chemistry Letters, 2013, 4, 1570-1577.

58. J.-Y. Liao, H.-P. Lin, H.-Y. Chen, D.-B. Kuang and C.-Y. Su, Journal of Materials Chemistry, 2012, 22, 1627-1633.

59. S. Ito, S. Zakeeruddin, R. Humphry-Baker, P. Liska, R. Charvet, P. Comte, M. Nazeeruddin, P. Péchy, M. Takata, H. Miura, S. Uchida and M. Grätzel, Advanced Materials, 2006, 18, 1202-1205.

60. H. Wang and L. M. Peter, The Journal of Physical Chemistry C, 2009, 113, 1812518133.

61. P. R. F. Barnes and B. C. O'Regan, The Journal of Physical Chemistry C, 2010, 114, 19134-19140.

62. L. Bertoluzzi and S. Ma, Physical Chemistry Chemical Physics, 2013, 15, 4283-4285.

63. E. J. W. Crossland, N. Noel, V. Sivaram, T. Leijtens, J. A. Alexander-Webber and H. J. Snaith, Nature, 2013, 495, 215-219. 
LEPABE - Laboratory for Process Engineering, Environment, Biotechnology and Energy

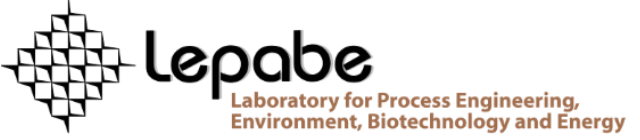

\section{U.PORTO}

FEUP FACULDADE DE ENGENHARIA DEPARTAMENTO DE UNIVERSIDADE DO PORTO $\mid$ ENGENHARIA QUÍMICA 